Check for updates

Cite this: RSC Adv., 2017, 7, 32367

Received 16th May 2017

Accepted 2nd June 2017

DOI: 10.1039/c7ra05512a

rsc.li/rsc-advances

\section{A phenomenological thermodynamic approach for evaluating the energetics involved in the discharge of lithium ion battery}

\begin{abstract}
V. Sudha ${ }^{a}$ and S. Harinipriya (D)*b
Processes involved in the discharge of a Li-ion battery are represented via thermochemical cycle, and the free energy involved in the process is expressed in terms of porosity, redox potential, energetics of solvation, diffusion, phase transition, and double-layer crossing of Li ions. In this study, the value of free energy involved in the discharge process of $\mathrm{LiMn}_{2} \mathrm{O}_{4}$ is evaluated. The maximum threshold of anode porosity and effect of Jahn-Teller distortion on the cathode material are predicted accurately. The maximum threshold of porosity for graphite anode is 0.4 to 0.5 and the Jahn-Teller distortion energy is predicted to be $-0.84 \mathrm{eV}$. Phase transition is predicted to occur at $0.5 \mathrm{SoC}$ of $\mathrm{Li}$ ions at the cathode. The predicted values are in satisfactory agreement with those reported in the literature.
\end{abstract}

\section{Introduction}

In systems engineering, modeling extensively permits the interpretation of experimental data, identification of rate-limiting steps and prediction of system behavior. It also provides a thorough understanding of the underlying physical processes. Mostly, for design and control, empirical models with fitted parameters are frequently used, although it is preferable to employ models based on microscopic physical or geometrical parameters as they are easy to interpret and optimize. Equivalent circuit models (ECMs) are widely used for electrochemical energy storage devices such as batteries, fuel cells, and supercapacitors in conjunction with impedance spectroscopy to fit and predict the performance and degradation of cells. ${ }^{1}$ The limitations of ECMs are their unambiguity in interpreting fitted circuit elements and predicting the nonlinear response of high operating currents. Hence, as an alternative, physics-based porous electrode models were developed for battery optimization and control. ${ }^{1}$ From first principles calculations employing quantum mechanics, bulk material properties, such as open-circuit potential and solid diffusivity, were predicted. ${ }^{2}$ To investigate and understand the multi-length and time scales of interfacial reactions, multi-phase, multi-component transport properties of coarse-grained continuum models were employed.

For applications such as in electric vehicles and electrical energy storage for solar and wind sources with high power and energy density requirements, mathematical modeling plays an inevitable role in the development of new intercalation materials, electrode microstructures, battery architectures, etc. The

${ }^{a}$ Department of Chemistry, SRM University, Kattankulathur, 603203, India

${ }^{b}$ Electrochemical Systems Lab, SRM Research Institute, SRM University, Kattankulathur, 603203, India.E-mail: harinipriya.s@res.srmuniv.ac.in standard modeling methodology was provided by Newman et $\mathrm{al}^{3}$ via the porous electrode theory for battery simulations. ${ }^{3}$ According to this theory, transport is modeled via volumeaveraged conservation equations for Li-ion batteries. ${ }^{4}$ The active particles are assumed as hard spheres into which Li ion intercalation occurs via isotropic linear diffusion..$^{5,6}$ For phaseseparating materials, such as $\mathrm{LiFePO}_{4}$, every particle is assumed to possess a spherical phase boundary, which moves as a shrinking core where one phase displaces the other. ${ }^{7-9}$ In these models, the local Nernst equilibrium potential is fitted to the global open-circuit voltage of the cell, and the non-uniform composition is neglected. Thus, a voltage plateau is observed for the porous electrode. ${ }^{10-13}$ For thermodynamic consistency, all these phenomena should be derived from common thermodynamic principles and cannot be independently fitted to the experimental data.

Recently, Smith, Garcia and Horn analyzed the effects of a microstructure on battery performance for various sizes and shapes of particles in a $\mathrm{Li}_{x} \mathrm{C}_{6} / \mathrm{Li}_{x} \mathrm{CoO}$ cell. ${ }^{14}$ The study used 3D image reconstruction of a real battery microstructure by focused ion beam milling, which has led to detailed studies of microstructural effects in porous electrodes. ${ }^{15-17}$ Additionally, it has also become possible to observe Li-ion transport at the scale of individual particles in porous Li-ion battery electrodes, ${ }^{18,19}$ which can be of much value in testing the dynamical predictions of new mathematical models.

The new theory has led to a quantitative understanding of intercalation dynamics in single nanoparticles of $\mathrm{LiFePO}_{4}$. Bai, Cogswell and Bazant ${ }^{12}$ generalized the Butler-Volmer equation using variational chemical potentials and used it to develop a mathematical theory of the suppression of phase separation in $\mathrm{LiFePO}_{4}$ nanoparticles with increasing current. This phenomenon helps to explain the remarkable performance of 
nano-LFP, as also suggested by Malik and Ceder based on bulk free-energy calculations, ${ }^{20}$ but the theory shows that it is entirely controlled by faradaic reactions at the particle surface. ${ }^{12,13}$ Cogswell and Bazant ${ }^{12}$ showed that including elastic coherency strain in the model leads to a quantitative theory of phase morphology and Li solubility. Experimental data for different particle sizes and temperatures can be fitted with only two parameters (the gradient penalty and regular solution parameter). The present study aims to develop a phenomenological thermodynamic approach incorporating electrolyte transport, electron transport, electrochemical kinetics, and phase separation to evaluate the free energy involved in the discharge process of Li-ion batteries. This leads to the application of thermodynamics for macroscopic phase transformations in porous electrodes for Li-ion batteries.

\section{Methodology and phenomenological thermodynamic derivations}

Processes involved in a Li-ion battery can be represented via the following thermochemical cycle: (Schemes 1 and 2).

In the case of $\mathrm{LiMn}_{2} \mathrm{O}_{4}$ or any cathode material undergoing phase transformation, the last step is complicated due to the formation of Li-rich and deficient phases. The phase transformation can be represented as follows:

$$
\mathrm{Li}_{(\mathrm{S})} \leftrightarrow \mathrm{Li}_{x} \mathrm{Mn}_{2} \mathrm{O}_{4}{ }^{(1-x)} \text { (two phases formed) } \leftrightarrow \mathrm{LiMn}_{2} \mathrm{O}_{4}
$$

Further lithiation leads to complication for the entering $\mathrm{Li}$ ions. The ions have to find and occupy the vacant sites and hence, require additional energy to get further lithiated. They have to randomly travel at the cathode surface and occupy the vacant sites to completely discharge the battery. Thus, there exists a voltage plateau over a long time in these types of cathode materials. This can also be attributed to the low diffusivity of $\mathrm{Li}$ ions in $\mathrm{Mn}_{2} \mathrm{O}_{4}$ lattice.

$$
\Delta G_{\mathrm{add}}=\Delta G_{\mathrm{occu}}-\Delta G_{\mathrm{unoccu}}
$$

Therefore, the energetics of the entire discharge process can be written as

$$
\begin{aligned}
\Delta G_{\text {process }}= & \Delta G_{\mathrm{ox}}^{\mathrm{a}}+\Delta G_{\mathrm{diff}}^{\mathrm{a}}+\Delta G^{\mathrm{a} / \mathrm{e}}+\Delta G_{\mathrm{sol}}+\Delta G_{\mathrm{diff}}^{\mathrm{sol}}+\Delta G^{\mathrm{c} / \mathrm{e}} \\
& +\Delta G_{\text {desol }}+\Delta G_{\mathrm{red}}+\Delta G_{\mathrm{diff}}^{\mathrm{c}}
\end{aligned}
$$

and for phase transformation cathodes,

$$
\begin{aligned}
\Delta G_{\text {process }}= & \Delta G_{\mathrm{ox}}^{\mathrm{a}}+\Delta G_{\mathrm{diff}}^{\mathrm{a}}+\Delta G^{\mathrm{a} / \mathrm{e}}+\Delta G_{\mathrm{sol}}+\Delta G_{\mathrm{diff}}^{\mathrm{sol}}+\Delta G^{\mathrm{c} / \mathrm{e}} \\
& +\Delta G_{\text {desol }}+\Delta G_{\mathrm{red}}+\Delta G_{\mathrm{diff}}^{\mathrm{c}}+\Delta G_{\mathrm{add}}
\end{aligned}
$$

(I) $\Delta G_{\mathrm{ox}}^{\mathrm{a}}=$ free energy change involved in the oxidation of $\mathrm{Li}$ to $\mathrm{Li}^{+}$at the anode (solid-phase oxidation) $=-F E^{\mathrm{a}}$, where $E^{\mathrm{a}}$ is the oxidation potential of the anodic reaction

$$
\mathrm{Li}_{x} \mathrm{C}_{6} \rightarrow x \mathrm{Li}^{+}+6 \mathrm{C}+x e
$$

(II) $\Delta G_{\text {diff }}^{\mathrm{a}}=$ free energy change involved in the diffusion of $\mathrm{Li}$ ions at the anode (solid-phase diffusion)

$$
\Delta G_{\mathrm{diff}}^{\mathrm{a}}=\text { charge } \times \text { potential }
$$

The charge, $Q$, based on Fick's second law of diffusion for short time approximation, $t \leq \frac{R^{2}}{D^{\prime}}$ is

$$
Q= \pm \frac{2 F A \sqrt{D_{\mathrm{i}} t}}{\sqrt{\pi}}\left(C^{\mathrm{ini}}-C^{\mathrm{aft}}\right) ;+=\text { discharge },-=\text { charge }
$$

where $F=$ Faraday's constant; $A=$ effective surface area per unit mass of the electrode; $t=$ time elapsed from the beginning of the potential step; $D_{\mathrm{i}}=$ diffusion coefficient of $\mathrm{Li}^{+}$in the corresponding electrode; $C^{\text {ini }}=$ initial concentration of $\mathrm{Li}$ ions before applying the potential and $C^{\text {aft }}=$ final concentration of $\mathrm{Li}$ ions after applying the potential.

$$
\begin{aligned}
& \text { Hence, at } t \leq \frac{R^{2}}{D} \\
& G_{\text {diff }}^{\mathrm{a}}=\frac{2 F A_{\mathrm{a}} V_{\mathrm{a}}\left(C_{\mathrm{a}}^{\mathrm{ini}}-C_{\mathrm{a}}^{\mathrm{aft}}\right) \sqrt{D_{\mathrm{a}} t}}{\sqrt{\pi}}
\end{aligned}
$$

where $V_{\mathrm{a}}=$ potential at that particular SoC; $R=$ maximum length of the diffusion path (particle radius; in the present case, $R$ is the ionic radius of $\mathrm{Li}^{+}$and $D$ is the anode thickness).

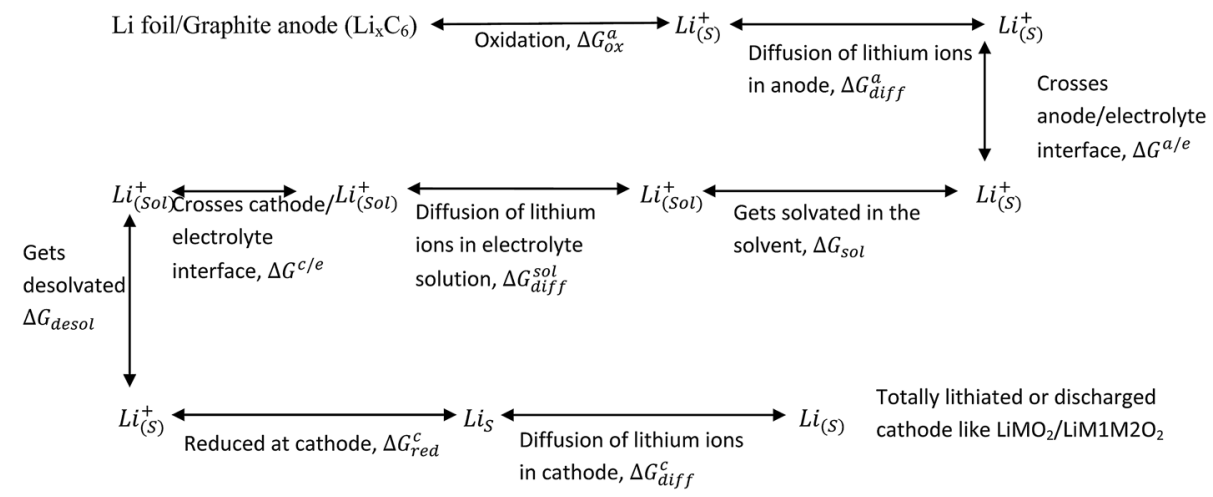

Scheme 1 Processes involved in the discharging of Li-ion cell (porosity and phase transformation are not taken into consideration). Assumptions: complete isotropicity and no porosity in the electrodes. 


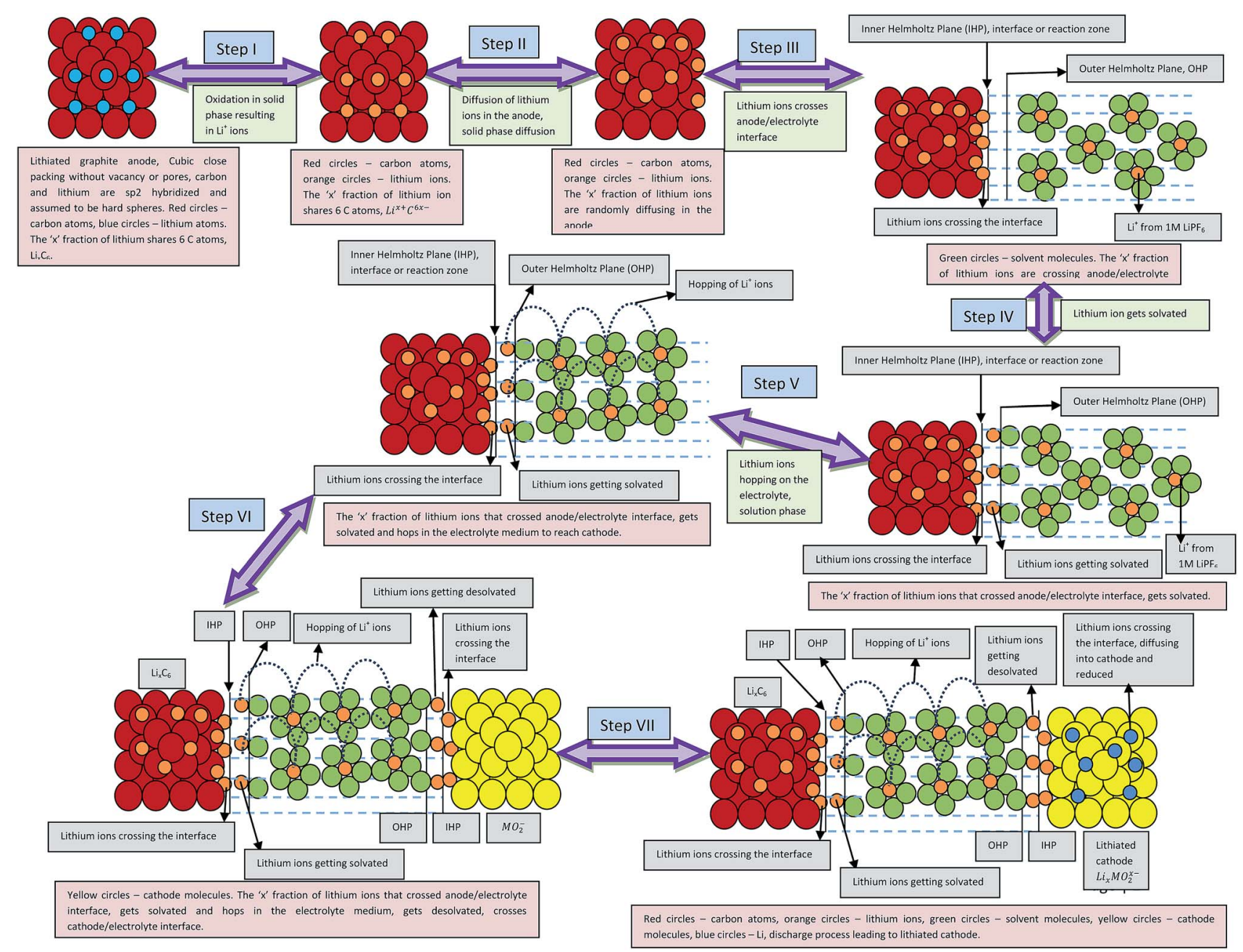

Scheme 2 Illustrative representation of the discharge process in lithium ion battery. Assumptions: electrodes are devoid of porosity.

(III) $\Delta G^{\mathrm{a} / \mathrm{e}}=$ free energy change involved in the escape of Li ions from the solid/solution interface (anode/electrolyte). The excess energy required for an ion or electron to escape to vacuum from the solution phase or vice versa is called its surface potential, ${ }^{22} \chi_{\mathrm{Li}^{+} / \text {anode }}$

$$
\Delta G^{\mathrm{a} / \mathrm{e}}=F \chi_{\mathrm{Li}^{+} / \text {anode }}
$$

(IV) $\Delta G_{\text {sol }}=$ solvation energy of $\mathrm{Li}^{+}$in EC/DEC $(1: 1)$ binary solvent.

The modified Born equation for estimating the solvation energy of ions in organic solvents is derived ${ }^{23}$ as

$$
-\Delta G_{\mathrm{sol}}=\frac{q^{2}}{2}\left[\left(1-\frac{1}{D_{\mathrm{e}}}\right)\left(\frac{1}{r_{1}}-\frac{1}{r_{2}}\right)+\left(1-\frac{1}{D}\right)\left(\frac{1}{r_{2}}\right)\right]
$$

where $D_{\mathrm{e}}=$ dielectric constant due to electron polarization of the atoms nearest to the central ion; $r_{1}=$ radius of the central ion $\left(\mathrm{Li}^{+}\right) ; r_{2}=$ distance to the center of the nearest atom of the solvent (the solvent molecules are oriented with their polar atoms toward the central ion); $D=$ static dielectric constant of the solvent, and $q=$ charge $=$ unity in the present case.
In the present scenario, where only a fraction " $x$ " of $\mathrm{Li}^{+}$gets solvated, $\Delta G_{\text {sol }}$ can be written as

$$
-\Delta G_{\text {sol }}=\frac{x}{2}\left[\left(1-\frac{1}{D_{\mathrm{e}}}\right)\left(\frac{1}{r_{1}}-\frac{1}{r_{2}}\right)+\left(1-\frac{1}{D}\right)\left(\frac{1}{r_{2}}\right)\right]
$$

EC/DEC being a binary solvent, $D_{\mathrm{e}}$ and $D$ are written as an average of the two solvents:

$$
D_{\mathrm{e}}=\frac{\left(D_{\mathrm{e}, \mathrm{EC}}+D_{\mathrm{e}, \mathrm{DEC}}\right)}{2}
$$

and

$$
D=\frac{\left(D_{\mathrm{EC}}+D_{\mathrm{DEC}}\right)}{2}
$$

Herein, Li ions interact with the solvent molecules via the carbonyl oxygen atoms, and hence, $r_{2}$ can be written in terms of partial $\mathrm{Li}^{\delta+}-\mathrm{O}^{\delta-}$ bond distance (half the covalent bond distance of $\mathrm{Li}-\mathrm{O}$ bond). Therefore, 


$$
\begin{aligned}
-\Delta G_{\mathrm{sol}}= & \frac{x}{2}\left[\left(1-\frac{2}{\left(D_{\mathrm{e}, \mathrm{EC}}+D_{\mathrm{e}, \mathrm{DEC}}\right)}\right)\left(\frac{1}{r_{\mathrm{Li}^{+}}}-\frac{2}{r_{\mathrm{Li}-\mathrm{O}}}\right)\right. \\
& \left.+\left(1-\frac{2}{\left(D_{\mathrm{EC}}+D_{\mathrm{DEC}}\right)}\right)\left(\frac{2}{r_{\mathrm{Li}-\mathrm{O}}}\right)\right]
\end{aligned}
$$

(V) $\Delta G_{\text {diff }}^{\text {sol }}=$ free energy change involved in the diffusion of $\mathrm{Li}^{+}$in an electrolytic solution. Since the hopping mechanism of $\mathrm{Li}^{+}$in solution phase involves partial $\mathrm{Li}^{\delta+}-\mathrm{O}^{\delta-}$ bond formation between $\mathrm{Li}$ ions and carbonyl oxygen atom of the solvent molecules, $\Delta G_{\text {diff }}^{\text {sol }}$ can be written as follows:

$$
\Delta G_{\text {diff }}^{\text {sol }}=-\frac{\Delta G_{\text {sol }}^{\mathrm{EC}}}{\mathrm{SN}^{\mathrm{EC}}}-\frac{\Delta G_{\mathrm{sol}}^{\mathrm{DEC}}}{\mathrm{SN}^{\mathrm{DEC}}}+\frac{\Delta G_{\mathrm{Li}-\mathrm{O}}^{\mathrm{form}}}{2 \mathrm{SN}^{\mathrm{EC}} \mathrm{SN}^{\mathrm{DEC}}}
$$

where

$$
-\Delta G_{\mathrm{sol}}^{\mathrm{EC}}=\frac{1}{2}\left[\left(1-\frac{1}{D_{\mathrm{e}}^{\mathrm{EC}}}\right)\left(\frac{1}{r_{\mathrm{Li}^{+}}}-\frac{2}{r_{\mathrm{Li}-\mathrm{O}}}\right)+\left(1-\frac{1}{D^{\mathrm{EC}}}\right)\left(\frac{2}{r_{\mathrm{Li}-\mathrm{O}}}\right)\right]
$$

Analogously,

$$
\begin{aligned}
-\Delta G_{\mathrm{sol}}^{\mathrm{DEC}}= & \frac{1}{2}\left[\left(1-\frac{1}{D_{\mathrm{e}}^{\mathrm{DEC}}}\right)\left(\frac{1}{r_{\mathrm{Li}^{+}}}-\frac{2}{r_{\mathrm{Li}-\mathrm{O}}}\right)+\left(1-\frac{1}{D^{\mathrm{DEC}}}\right)\right. \\
& \left.\times\left(\frac{2}{r_{\mathrm{Li}-\mathrm{O}}}\right)\right]
\end{aligned}
$$

Therefore, eqn (14) becomes

$$
\begin{aligned}
\Delta G_{\mathrm{diff}}^{\mathrm{sol}}= & \frac{1}{2}\left\{\frac { 1 } { \mathrm { SN } ^ { \mathrm { EC } } } \left[\left(1-\frac{1}{D_{\mathrm{e}}^{\mathrm{EC}}}\right)\left(\frac{1}{r_{\mathrm{Li}^{+}}}-\frac{2}{r_{\mathrm{Li}-\mathrm{O}}}\right)+\left(1-\frac{1}{D^{\mathrm{EC}}}\right)\right.\right. \\
& \left.\times\left(\frac{2}{r_{\mathrm{Li}-\mathrm{O}}}\right)\right]+\frac{1}{\mathrm{SN}^{\mathrm{DEC}}}\left[\left(1-\frac{1}{D_{\mathrm{e}}^{\mathrm{DEC}}}\right)\left(\frac{1}{r_{\mathrm{Li}^{+}}}-\frac{2}{r_{\mathrm{Li}-\mathrm{O}}}\right)\right. \\
& \left.\left.+\left(1-\frac{1}{D^{\mathrm{DEC}}}\right)\left(\frac{2}{r_{\mathrm{Li}-\mathrm{O}}}\right)\right]\right\}+\frac{\Delta G_{\mathrm{Li}-\mathrm{O}}^{\mathrm{form}}}{2 \mathrm{SN}^{\mathrm{EC}} \mathrm{SN}^{\mathrm{DEC}}}
\end{aligned}
$$

where the solvation numbers $\mathrm{SN}^{\mathrm{EC}}$ and $\mathrm{SN}^{\mathrm{DEC}}$ of $\mathrm{Li}^{+}$in $\mathrm{EC}$ and DEC solvents can be empirically written as the volume ratio of the ion to the solvent molecule (the ions and solvents are considered to be hard spheres), and hence, ${ }^{\mathbf{2 4 , 2 5}}$

$$
\mathrm{SN}^{\mathrm{EC}}=\frac{r_{\mathrm{Li}^{+}}{ }^{3}}{r_{\mathrm{EC}}{ }^{3}}
$$

and

$$
\mathrm{SN}^{\mathrm{DEC}}=\frac{r_{\mathrm{Li}^{+}}{ }^{3}}{r_{\mathrm{DEC}}{ }^{3}}
$$

where $r_{\mathrm{Li}^{+}}{ }^{3}$ and $r_{\mathrm{EC}}{ }^{3}, r_{\mathrm{DEC}}{ }^{3}$ denote the cubic radius of the $\mathrm{Li}$ ion and the solvents EC and DEC, respectively. Therefore, eqn (16) becomes $^{22}$

$$
\begin{aligned}
\Delta G_{\mathrm{diff}}^{\mathrm{sol}}= & \frac{1}{2}\left\{\frac { r _ { \mathrm { EC } } { } ^ { 3 } } { r _ { \mathrm { Li } ^ { + } } { } ^ { 3 } } \left[\left(1-\frac{1}{D_{\mathrm{e}}^{\mathrm{EC}}}\right)\left(\frac{1}{r_{\mathrm{Li}^{+}}}-\frac{2}{r_{\mathrm{Li}-\mathrm{O}}}\right)+\left(1-\frac{1}{D^{\mathrm{EC}}}\right)\right.\right. \\
& \left.\times\left(\frac{2}{r_{\mathrm{Li}-\mathrm{O}}}\right)\right]+\frac{r_{\mathrm{DEC}}}{r_{\mathrm{Li}^{+}}{ }^{3}}\left[\left(1-\frac{1}{D_{\mathrm{e}}^{\mathrm{DEC}}}\right)\left(\frac{1}{r_{\mathrm{Li}^{+}}}-\frac{2}{r_{\mathrm{Li}-\mathrm{O}}}\right)\right. \\
& \left.\left.+\left(1-\frac{1}{D^{\mathrm{DEC}}}\right)\left(\frac{2}{r_{\mathrm{Li}-\mathrm{O}}}\right)\right]\right\}+\frac{r_{\mathrm{EC}}{ }^{3} r_{\mathrm{DEC}^{3}} \Delta G_{\mathrm{Li}-\mathrm{O}}^{\mathrm{form}}}{2 r_{\mathrm{Li}^{+}}{ }^{6}}
\end{aligned}
$$

here $\Delta G_{\mathrm{Li}-\mathrm{O}}^{\text {form }}$ represents the free energy of formation of $\mathrm{Li}-\mathrm{O}$ bond.

(VI) $\Delta G^{\text {c/e }}=$ free energy change involved in the process of crossing the electrolyte/cathode interface (solution/ vacuum $)^{24}$

$$
\Delta G^{\mathrm{c} / \mathrm{e}}=-F \chi_{\mathrm{Li}^{+} / \text {cathode }}
$$

(VII) $\Delta G_{\text {desol }}=$ free energy change involved in the desolvation of the fraction " $y$ " of the Li ions entering the cathode

$$
\begin{aligned}
\Delta G_{\mathrm{desol}}= & \frac{y}{2}\left\{\left[\left(1-\frac{2}{\left(D_{\mathrm{e}, \mathrm{EC}}+D_{\mathrm{e}, \mathrm{DEC}}\right)}\right)\left(\frac{1}{r_{\mathrm{Li}^{+}}}-\frac{2}{r_{\mathrm{Li}-\mathrm{O}}}\right)\right]\right. \\
& \left.+\left[\left(1-\frac{2}{\left(D_{\mathrm{EC}}+D_{\mathrm{DEC}}\right)}\right)\left(\frac{2}{r_{\mathrm{Li}-\mathrm{O}}}\right)\right]\right\}
\end{aligned}
$$

(VIII) $\Delta G_{\text {red }}=$ free energy change involved in the reduction of $\mathrm{Li}$ ions at the cathode (solid-phase reduction reaction)

$$
\Delta G_{\text {red }}=-F E^{\mathrm{c}}
$$

where $E^{\mathrm{c}}$ is the solid-phase cathodic reaction potential.

(IX) $\Delta G_{\text {diff }}^{\text {c }}=$ free energy change during the diffusion of $\mathrm{Li}$ ions at the cathode (solid-phase diffusion). Analogous to the

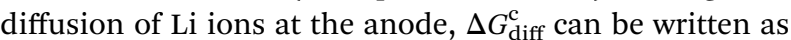

$$
\Delta G_{\text {diff }}^{\mathrm{c}}=\frac{2 F A_{\mathrm{c}} V_{\mathrm{c}}\left(C_{\mathrm{c}}^{\mathrm{ini}}-C_{\mathrm{c}}^{\mathrm{aft}}\right) \sqrt{D_{\mathrm{c}} t}}{\sqrt{\pi}}
$$

where $D_{\mathrm{c}}$ is the diffusion coefficient of Li ions at the cathode, and $C_{\mathrm{c}}^{\mathrm{ini}}$ and $C_{\mathrm{c}}^{\mathrm{aft}}$ are the initial and final concentrations of $\mathrm{Li}$ ions before and after applying the voltage, respectively.

(X) $\Delta G_{\text {add }}=$ excess energy required by the Li ions to find an unoccupied site at the cathode and $z$ represents the total number of sites occupied by $\mathrm{Li}^{+}$

$$
\Delta G_{\text {add }}=\Delta G_{\text {occu }}-\Delta G_{\text {unoccu }}
$$

Occupied sites are $\mathrm{Li}_{z} \mathrm{Mn}_{2} \mathrm{O}_{4}{ }^{(1-z)}$ and unoccupied sites are $(1$ $-z) \mathrm{Mn}_{2} \mathrm{O}_{4}{ }^{-}$. Therefore

$$
\Delta G_{\text {occu }}=z \Delta G_{\mathrm{Li}-\mathrm{Mn}_{2} \mathrm{O}_{4}}^{\mathrm{form}}
$$

and $\Delta G_{\text {unoccu }}=$ ground state energy of $\mathrm{Mn}_{2} \mathrm{O}_{4}{ }^{-}$in its native state, $\Delta G_{\mathrm{gs}}^{\mathrm{Mn}_{2} \mathrm{O}_{4}{ }^{-}}$. Hence,

$$
\Delta G_{\mathrm{add}}=z \Delta G_{\mathrm{Li}-\mathrm{Mn}_{2} \mathrm{O}_{4}^{-}}^{\mathrm{form}}-(1-z) \Delta G_{\mathrm{gs}}^{\mathrm{Mn}_{2} \mathrm{O}_{4}^{-}}
$$


Thus, eqn (2) can be written as

$$
\begin{aligned}
\Delta G_{\text {process }}= & -F\left(E^{\mathrm{a}}+E^{\mathrm{c}}-\chi_{\mathrm{Li}^{+} / \text {anode }}+\chi_{\mathrm{Li}^{+} / \text {cathode }}\right)+2 F \sqrt{\frac{t}{\pi}}\left[\left(A_{\mathrm{a}} V_{\mathrm{a}} \sqrt{D_{\mathrm{a}}}\left(C_{\mathrm{a}}^{\mathrm{ini}}-C_{\mathrm{a}}^{\mathrm{aft}}\right)\right)+\left(A_{\mathrm{c}} V_{\mathrm{c}} \sqrt{D_{\mathrm{c}}}\left(C_{\mathrm{c}}^{\mathrm{ini}}-C_{\mathrm{c}}^{\mathrm{aft}}\right)\right)\right] \\
& +\frac{(y-x)}{2}\left[\left(1-\frac{2}{\left(D_{\mathrm{e}, \mathrm{EC}}+D_{\mathrm{e}, \mathrm{DEC}}\right)}-\frac{2}{r_{\mathrm{Li}+}+\mathrm{O}}\right)\right]+\left[\left(1-\frac{2}{\left(D_{\mathrm{EC}}+D_{\mathrm{DEC}}\right)}\right)\right] \\
& \left.\left.+\frac{1}{2}\left\{\frac{r_{\mathrm{EC}}{ }^{3}}{r_{\mathrm{Li}-\mathrm{O}}}\right)\right]\left(1-\frac{1}{D_{\mathrm{e}}^{\mathrm{EC}}}\right)\left(\frac{1}{r_{\mathrm{Li}^{+}}}-\frac{2}{r_{\mathrm{Li}-\mathrm{O}}}\right)+\left(1-\frac{1}{D^{\mathrm{EC}}}\right)\left(\frac{2}{r_{\mathrm{Li}-\mathrm{O}}}\right)\right] \\
& \left.+\frac{r_{\mathrm{DEC}^{3}}}{r_{\mathrm{Li}^{+}}{ }^{3}}\left[\left(1-\frac{1}{D_{\mathrm{e}}^{\mathrm{DEC}}}\right)\left(\frac{1}{r_{\mathrm{Li}^{+}}}-\frac{2}{r_{\mathrm{Li}-\mathrm{O}}}\right)+\left(1-\frac{1}{D^{\mathrm{DEF}}}\right)\left(\frac{2}{r_{\mathrm{Li}-\mathrm{O}}}\right)\right]\right\}+\frac{r_{\mathrm{EC}}{ }^{3} r_{\mathrm{DEC}^{3} \Delta G_{\mathrm{Li}-\mathrm{O}}^{\mathrm{form}}}^{2 r_{\mathrm{Li}^{+}}}}{}
\end{aligned}
$$

for the phase transformation electrode,

$$
\begin{aligned}
& \Delta G_{\text {process }}=-F\left(E^{\mathrm{a}}+E^{\mathrm{c}}-\chi_{\mathrm{Li}^{+} / \text {anode }}+\chi_{\mathrm{Li}^{+} / \text {cathode }}\right)+2 F \sqrt{\frac{t}{\pi}}\left[\left(A_{\mathrm{a}} V_{\mathrm{a}} \sqrt{D_{\mathrm{a}}}\left(C_{\mathrm{a}}^{\mathrm{ini}}-C_{\mathrm{a}}^{\mathrm{aft}}\right)\right)+\left(A_{\mathrm{c}} V_{\mathrm{c}} \sqrt{D_{\mathrm{c}}}\left(C_{\mathrm{c}}^{\mathrm{ini}}-C_{\mathrm{c}}^{\mathrm{aft}}\right)\right)\right] \\
& +\frac{(y-x)}{2}\left[\left(1-\frac{2}{\left(D_{\mathrm{e}, \mathrm{EC}}+D_{\mathrm{e}, \mathrm{DEC}}\right)}\right)\left(\frac{1}{r_{\mathrm{Li}^{+}}}-\frac{2}{r_{\mathrm{Li}-\mathrm{O}}}\right)\right]+\left[\left(1-\frac{2}{\left(D_{\mathrm{EC}}+D_{\mathrm{DEC}}\right)}\right)\left(\frac{2}{r_{\mathrm{Li}-\mathrm{O}}}\right)\right] \\
& +\frac{1}{2}\left\{\frac{r_{\mathrm{EC}}^{3}}{r_{\mathrm{Li}^{+}}{ }^{3}}\left[\left(1-\frac{1}{D_{\mathrm{e}}^{\mathrm{EC}}}\right)\left(\frac{1}{r_{\mathrm{Li}^{+}}}-\frac{2}{r_{\mathrm{Li}-\mathrm{O}}}\right)+\left(1-\frac{1}{D^{\mathrm{EC}}}\right)\left(\frac{2}{r_{\mathrm{Li}-\mathrm{O}}}\right)\right]+\frac{r_{\mathrm{DEC}}{ }^{3}}{r_{\mathrm{Li}^{+}}{ }^{3}}\left[\left(1-\frac{1}{D_{\mathrm{e}}^{\mathrm{DEC}}}\right)\left(\frac{1}{r_{\mathrm{Li}^{+}}}-\frac{2}{r_{\mathrm{Li}-\mathrm{O}}}\right)\right.\right. \\
& \left.\left.+\left(1-\frac{1}{D^{\mathrm{DEF}}}\right)\left(\frac{2}{r_{\mathrm{Li}-\mathrm{O}}}\right)\right]\right\}+\frac{r_{\mathrm{EC}}{ }^{3} r_{\mathrm{DEC}}{ }^{3} \Delta G_{\mathrm{Li}-\mathrm{O}}^{\mathrm{form}}}{2 r_{\mathrm{Li}^{+}}{ }^{6}}+z \Delta G_{\mathrm{Li}-\mathrm{Mn}_{2} \mathrm{O}_{4^{-}}}^{\mathrm{form}}-(1-z) \Delta G_{\mathrm{gs}^{-}}^{\mathrm{Mn}_{2} \mathrm{O}_{4}{ }^{-}}
\end{aligned}
$$

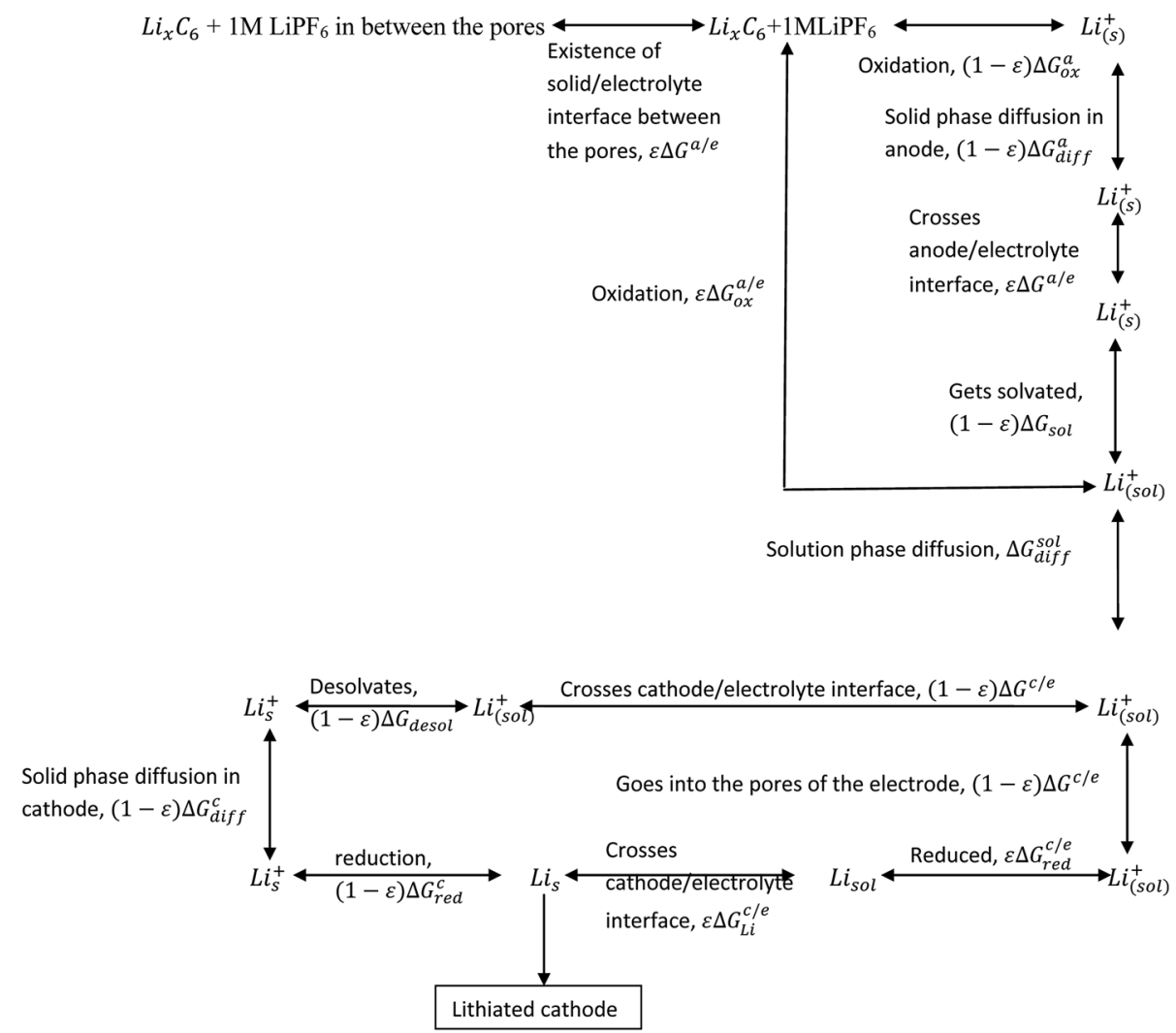

Scheme 3 Processes involved in the discharge of Li-ion battery (electrodes with porosity). 
Eqn (28) and (29) represent the free energy change involved in the entire discharge process of a Li-ion battery, where the electrodes are assumed to be isotropic and no porosity occurs. Eqn (29) takes into account the phase transformation at the cathode.

When the electrodes are porous in nature, the electrolyte seeps through the electrode and the solid/electrolyte interface (SEI) comes into existence on the electrode surface. This makes the entire process complicated. The discharge process can now be written as given in Scheme 3.

In the case of cathodes undergoing phase transformation, the following additional term is included:

$$
(1-\varepsilon) \Delta G_{\mathrm{add}}=(1-\varepsilon)\left[z \Delta G_{\mathrm{Li}-\mathrm{Mn}_{2} \mathrm{O}_{4^{-}}}^{\mathrm{form}}-(1-z) \Delta G_{\mathrm{gs}}^{\mathrm{Mn}_{2} \mathrm{O}_{4}{ }^{-}}\right]
$$

where $e$ represents porosity. Thus, the free energy for the entire process can now be written as

$$
\begin{aligned}
\Delta G_{\text {process }}= & 2 \varepsilon \Delta G^{\mathrm{a} / \mathrm{e}}+\varepsilon \Delta G_{\mathrm{ox}}^{\mathrm{a} / \mathrm{e}}+(1-\varepsilon) \Delta G_{\mathrm{ox}}^{\mathrm{a}}+(1-\varepsilon) \Delta G_{\mathrm{diff}}^{\mathrm{a}} \\
& +(1-\varepsilon) \Delta G^{\mathrm{sol}}+\Delta G_{\mathrm{diff}}^{\mathrm{sol}}+2(1-\varepsilon) \Delta G^{\mathrm{c} / \mathrm{e}}+\varepsilon \Delta G_{\mathrm{red}}^{\mathrm{c} / \mathrm{e}} \\
& +\varepsilon \Delta G_{\mathrm{Li}}^{\mathrm{c} / \mathrm{e}}+(1-\varepsilon) \Delta G_{\mathrm{desol}}+(1-\varepsilon) \Delta G_{\mathrm{red}}^{\mathrm{C}} \\
& +(1-\varepsilon) \Delta G_{\mathrm{diff}}^{\mathrm{C}}
\end{aligned}
$$

and for $\mathrm{LiMn}_{2} \mathrm{O}_{4}$-type cathodes,

$$
\begin{aligned}
\Delta G_{\text {process }}= & 2 \varepsilon \Delta G^{\mathrm{a} / \mathrm{e}}+\varepsilon \Delta G_{\mathrm{ox}}^{\mathrm{a} / \mathrm{e}}+(1-\varepsilon) \Delta G_{\mathrm{ox}}^{\mathrm{a}}+(1-\varepsilon) \Delta G_{\text {diff }}^{\mathrm{a}} \\
& +(1-\varepsilon) \Delta G^{\mathrm{sol}}+\Delta G_{\mathrm{diff}}^{\mathrm{sol}}+2(1-\varepsilon) \Delta G^{\mathrm{c} / \mathrm{e}}+\varepsilon \Delta G_{\mathrm{red}}^{\mathrm{c} / \mathrm{e}} \\
& +\varepsilon \Delta G_{\mathrm{Li}}^{\mathrm{c} / \mathrm{e}}+(1-\varepsilon) \Delta G_{\text {desol }}+(1-\varepsilon) \Delta G_{\mathrm{red}}^{\mathrm{c}} \\
& +(1-\varepsilon) \Delta G_{\text {diff }}^{\mathrm{c}}+(1-\varepsilon) \\
& \times\left[z \Delta G_{\mathrm{Li}-\mathrm{Mn}_{2} \mathrm{O}_{4^{-}}}^{\mathrm{form}}-(1-z) \Delta G_{\mathrm{gs}}^{\mathrm{Mn}_{2} \mathrm{O}_{4}^{-}}\right]
\end{aligned}
$$

By incorporating the expressions for all terms from the previous section, eqn (31) and (32) become

$$
\begin{aligned}
\Delta G_{\text {process }}= & -\varepsilon F\left(E^{\mathrm{a} / \mathrm{e}}+E^{\mathrm{c} / \mathrm{e}}+\chi_{\mathrm{Li}}^{\mathrm{c} / \mathrm{e}}-2 \chi_{\mathrm{Li}^{+}}^{\mathrm{a} / \mathrm{e}}\right. \\
& +(1-\varepsilon) F\left\{-E^{\mathrm{a}}-E^{\mathrm{c}}-2 \chi_{\mathrm{Li}^{+}}^{\mathrm{c} / \mathrm{e}}+2 A_{\mathrm{a}} V_{\mathrm{a}}\left(C_{\mathrm{a}}^{\mathrm{ini}}-C_{\mathrm{a}}^{\mathrm{aft}}\right)\right. \\
& \times \sqrt{\frac{t D_{\mathrm{a}}}{\pi}}+2 A_{\mathrm{a}} V_{\mathrm{c}}\left(C_{\mathrm{a}}^{\mathrm{ini}}-C_{\mathrm{a}}^{\mathrm{aft}}\right) \sqrt{\frac{t D_{\mathrm{c}}}{\pi}} \\
& -\frac{(x-y)}{2 F}\left[\left(1-\frac{2}{\left(D_{\mathrm{e}, \mathrm{EC}}+D_{\mathrm{e}, \mathrm{DEC}}\right)}\right)\left(\frac{1}{r_{\mathrm{Li}}{ }^{+}}-\frac{2}{r_{\mathrm{Li}-\mathrm{O}}}\right)\right. \\
& \left.+\left(1-\frac{2}{\left(D_{\mathrm{e}, \mathrm{EC}}+D_{\mathrm{e}, \mathrm{DEC}}\right)}\right)\left(\frac{1}{r_{\mathrm{Li}-\mathrm{O}}}\right)\right] \\
& +\frac{r_{\mathrm{EC}}{ }^{3}}{2 r_{\mathrm{Li}^{+}}{ }^{3}}\left[\left(1-\frac{1}{D_{\mathrm{e}, \mathrm{EC}}}\right)-\frac{2}{r_{\mathrm{Li}-\mathrm{O}}}\right) \\
& \left.+\left(1-\frac{1}{r_{\mathrm{EC}}}\right)\left(\frac{2}{r_{\mathrm{Li}-\mathrm{O}}}\right)\right] \\
& +\frac{r_{\mathrm{DEC}}{ }^{3}}{2 r_{\mathrm{Li}^{+}}{ }^{3}}\left[\left(1-\frac{1}{D_{\mathrm{e}, \mathrm{DEC}}}\right)\left(\frac{1}{r_{\mathrm{Li}^{+}}}-\frac{2}{r_{\mathrm{Li}-\mathrm{O}}}\right)\right. \\
& \left.\left.+\left(1-\frac{1}{D_{\mathrm{DEC}}}\right)\left(\frac{2}{r_{\mathrm{Li}-\mathrm{O}}}\right)\right]+\frac{r_{\mathrm{EC}}{ }^{3} r_{\mathrm{DEC}}{ }^{3} \Delta G_{\mathrm{Li}-\mathrm{O}}^{\mathrm{form}}}{2 r_{\mathrm{Li}^{+}}{ }^{6}}\right\}
\end{aligned}
$$

and for phase transformation cathodes,

$$
\begin{aligned}
& \Delta G_{\text {process }}=-\varepsilon F\left(E^{\mathrm{a} / \mathrm{e}}+E^{\mathrm{c} / \mathrm{e}}+\chi_{\mathrm{Li}}^{\mathrm{c} / \mathrm{e}}-2 \chi_{\mathrm{Li}^{+}}^{\mathrm{a} / \mathrm{e}}\right) \\
& +(1-\varepsilon) F\left\{-E^{\mathrm{a}}-E^{\mathrm{c}}-2 \chi_{\mathrm{Li}^{+}}^{\mathrm{c} / \mathrm{e}}+2 A_{\mathrm{a}} V_{\mathrm{a}}\left(C_{\mathrm{a}}^{\mathrm{ini}}-C_{\mathrm{a}}^{\mathrm{aft}}\right)\right. \\
& \times \sqrt{\frac{t D_{\mathrm{a}}}{\pi}}+2 A_{\mathrm{a}} V_{\mathrm{c}}\left(C_{\mathrm{a}}^{\mathrm{ini}}-C_{\mathrm{a}}^{\mathrm{aft}}\right) \sqrt{\frac{t D_{\mathrm{c}}}{\pi}}-\frac{(x-y)}{2 F} \\
& \times\left[\left(1-\frac{2}{\left(D_{\mathrm{e}, \mathrm{EC}}+D_{\mathrm{e}, \mathrm{DEC}}\right)}\right)\left(\frac{1}{r_{\mathrm{Li}^{+}}}-\frac{2}{r_{\mathrm{Li}-\mathrm{O}}}\right)\right. \\
& \left.+\left(1-\frac{2}{\left(D_{\mathrm{EC}}+D_{\mathrm{DEC}}\right)}\right)\left(\frac{2}{r_{\mathrm{Li}-\mathrm{O}}}\right)\right] \\
& +\frac{r_{\mathrm{EC}}^{3}}{2 r_{\mathrm{Li}^{+}}{ }^{3}}\left[\left(1-\frac{1}{D_{\mathrm{e}, \mathrm{EC}}}\right)\left(\frac{1}{r_{\mathrm{Li}^{+}}}-\frac{2}{r_{\mathrm{Li}-\mathrm{O}}}\right)\right. \\
& \left.+\left(1-\frac{1}{D_{\mathrm{EC}}}\right)\left(\frac{2}{r_{\mathrm{Li}-\mathrm{O}}}\right)\right] \\
& +\frac{r_{\mathrm{DEC}}{ }^{3}}{2 r_{\mathrm{Li}^{+}}{ }^{3}}\left[\left(1-\frac{1}{D_{\mathrm{e}, \mathrm{DEC}}}\right)\left(\frac{1}{r_{\mathrm{Li}^{+}}}-\frac{2}{r_{\mathrm{Li}-\mathrm{O}}}\right)\right. \\
& \left.+\left(1-\frac{1}{D_{\mathrm{DEC}}}\right)\left(\frac{2}{r_{\mathrm{Li}-\mathrm{O}}}\right)\right] \frac{r_{\mathrm{EC}}{ }^{3} r_{\mathrm{DEC}}{ }^{3} \Delta G_{\mathrm{Li}-\mathrm{O}}^{\mathrm{form}}}{2 r_{\mathrm{Li}^{+}}{ }^{6}} \\
& \left.+z \Delta G_{\mathrm{Li}-\mathrm{Mn}_{2} \mathrm{O}_{4}^{-}}^{\mathrm{form}}-(1-z) \Delta G_{\mathrm{gs}}^{\mathrm{Mn}_{2} \mathrm{O}_{4}^{-}}\right\}
\end{aligned}
$$

Now, eqn (33) and (34) are the final form incorporating porosity in deriving the expression for the free energy involved in the discharge process of a Li-ion battery.

\section{Results and discussion}

Eqn (28), (29), (33), and (34) calculate the free energy involved in the discharge process of a Li-ion battery (i) without phase transition cathode and porosity, (ii) with phase transition cathode and no porosity, (iii) without porosity and with phase transition cathode, and (iv) with porosity and phase transition cathode, respectively. The individual contributing factors and free energies associated with the same are discussed in the following sections (Scheme 4).

\subsection{Free energy change involved in the process of Li-ion intercalation at the cathode and deintercalation at the anode}

The first term in eqn (28) accounts for the free energy change involved in Li-ion deintercalation at the anode (graphite) and intercalation at the cathode $\left(\mathrm{MnO}_{2}\right)$. The free energy change is represented as

$$
\Delta G_{\mathrm{I}}=-F\left(E^{\mathrm{a}}+E^{\mathrm{c}}-\chi_{\mathrm{Li}^{+} / \text {anode }}+\chi_{\mathrm{Li}^{+} / \text {cathode }}\right)
$$

Upon employing the values of all parameters in eqn (35), is obtained as $-550.050 \mathrm{~kJ} \mathrm{~mol}^{-1}$.

Parameters employed. $E^{\mathrm{c}}=4.1 \mathrm{eV}$ (for $\mathrm{Li}_{x} \mathrm{Mn}_{2-x} \mathrm{O}_{4}$ (ref. 26)), $E^{\mathrm{a}}=1.0 \mathrm{eV}$ (for graphite $\left.{ }^{21}\right), \chi_{\mathrm{Li}^{+} / \text {anode }}=-0.4 \mathrm{eV}\left(\right.$ for graphite ${ }^{22}$ ), $\chi_{\mathrm{Li}^{+} / \text {cathode }}=-0.2 \mathrm{eV}$ (for $\mathrm{Li}_{x} \mathrm{Mn}_{2-x} \mathrm{O}_{4}$ (ref. 22)).

$\Delta \boldsymbol{G}_{\mathrm{I}}$. The value of $-5.7 \mathrm{eV}$ obtained for $\Delta G_{\mathrm{I}}$ can be attributed to the negative sum of the work function of the electrodes during Li-ion intercalation and deintercalation. It is well 


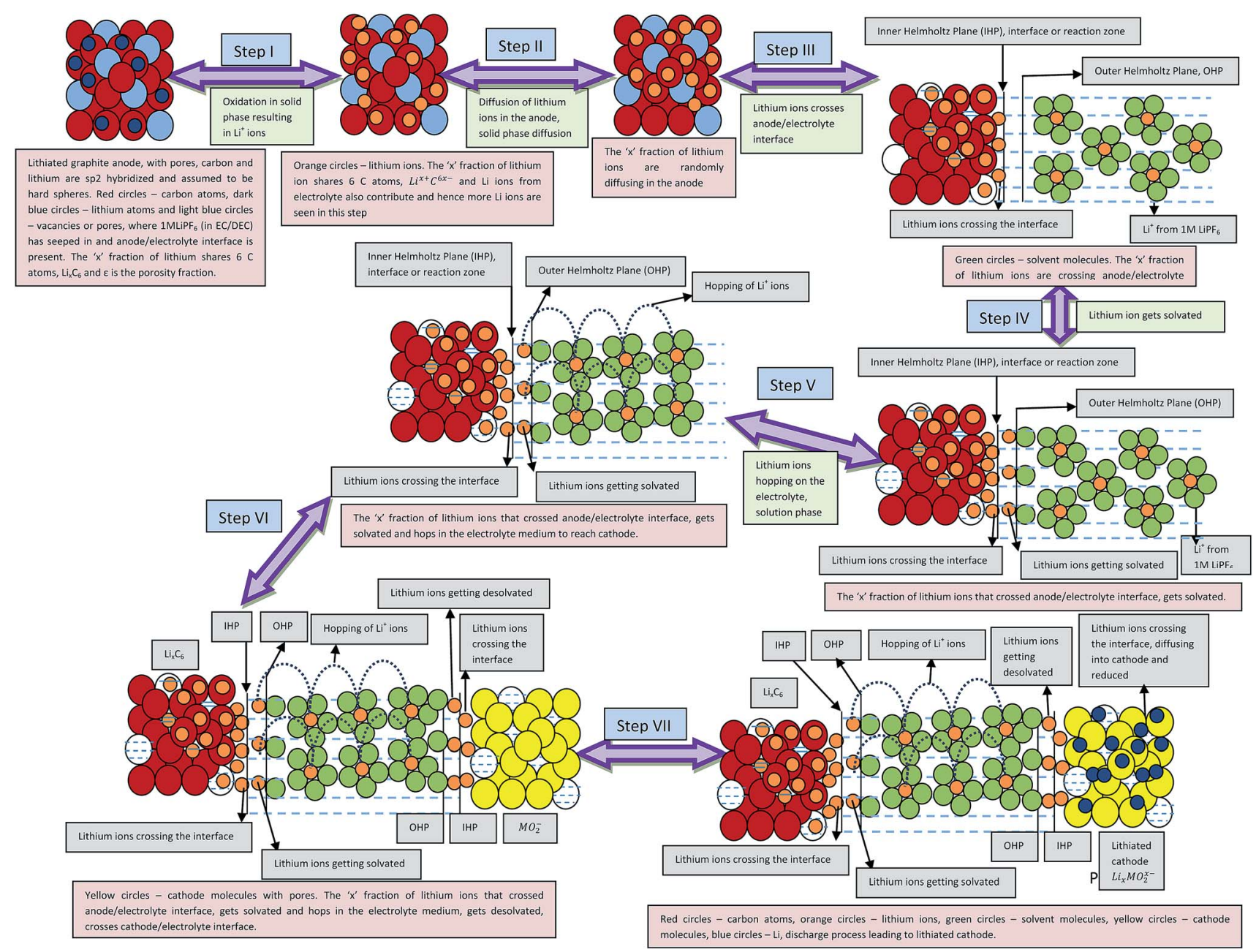

Scheme 4 Illustrative representation of the discharge process in lithium ion battery constituted by porous electrodes.

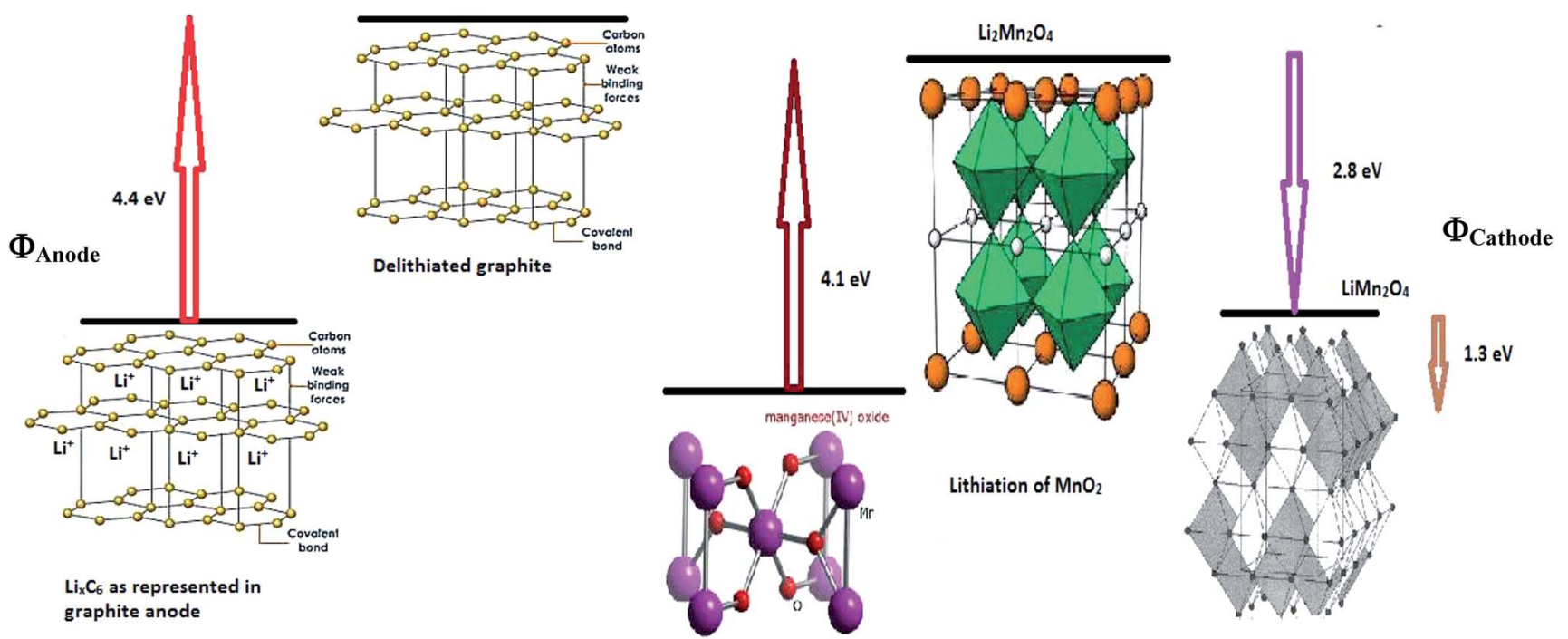

Scheme 5 Illustrative representation of the work function difference between anode and cathode during delithiation and lithiation, respectively. 


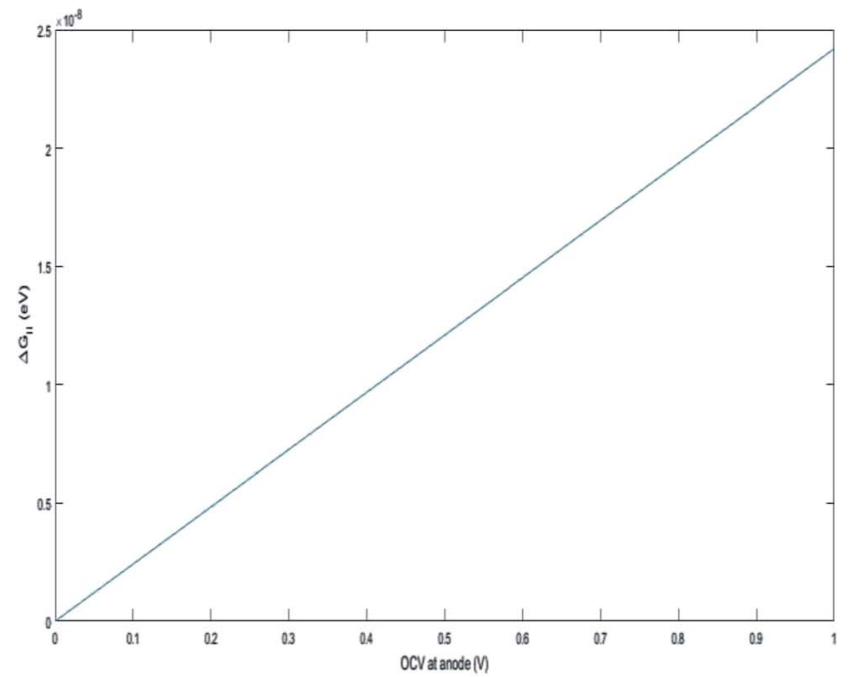

(a)

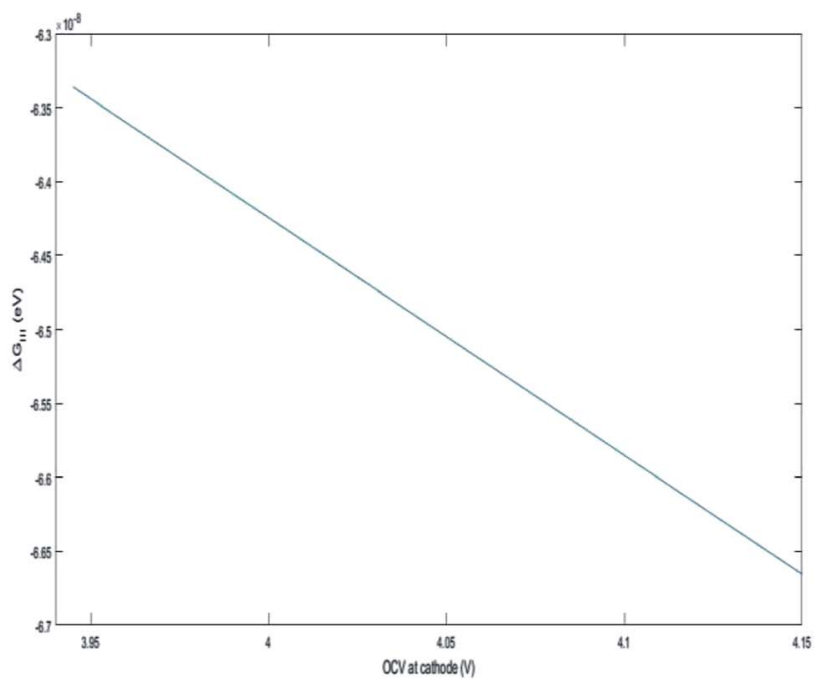

(b)

Fig. 1 Plot of $\Delta G_{\|}$and $\Delta G_{\|\|}$versus open-circuit potential at each SoC at (a) anode and (b) cathode at $\left(t=\frac{R^{2}}{D}\right)$.

known ${ }^{27-29}$ that Li-ion intercalation at the cathode $\mathrm{MnO}_{2}$ occurs in two stages and Fermi level of the cathode material varies in these two stages due to Jahn-Teller distortion of the $\mathrm{LiMn}_{2} \mathrm{O}_{4}$ octahedral lattice accompanied by significant crystal structure rearrangement. Upon Li-ion insertion, initially, all $\mathrm{Li}$ ions occupy the $16 \mathrm{c}$ sites, resulting in the chemical formula of $\mathrm{Li}_{2} \mathrm{Mn}_{2} \mathrm{O}_{4}$. All $\mathrm{Mn}$ ions reduce to $\mathrm{Mn}^{3+}$ from $\mathrm{Mn}^{4+}$ during the lithiation process. This lattice structure corresponds to a work function of $4.1 \mathrm{eV}$. Upon further lithiation, the geometry of the cathode further distorts from octahedral geometry to tetrahedral geometry, accounting for a work function value of $2.8 \mathrm{eV}$. Therefore, the total work function of the system at any fraction of Li-ion intercalation is seen as the difference in the work function of both lattice structures, i.e., $1.3 \mathrm{eV}$. The work function of bulk polycrystalline graphite is reported to be $4.4 \mathrm{eV}^{30}$ The sum of the work functions of the cathode and anode is $5.7 \mathrm{eV}$. This clearly indicates that $\mathrm{Li}$ has to utilize $4.4 \mathrm{eV}$ to deintercalate from the graphite anode and $4.4 \mathrm{eV}$ to intercalate at the $\mathrm{MnO}_{2}$ cathode; hence, the total free energy required for the process is the sum of the energy utilized to achieve the process. As per definition, $\Delta G$ is negative of the work done in a process, and $\Delta G_{\text {I }}$ becomes $-5.7 \mathrm{eV}, c a .-550.050 \mathrm{~kJ} \mathrm{~mol}^{-1}$. The entire process is illustratively represented in Scheme 5 .

\subsection{Free energy change involved in the diffusion of $\mathrm{Li}$ ions at the anode and cathode: solid-phase diffusion}

The second term in eqn (28) accounts for the free energy change involved in the Li-ion diffusion at the anode (graphite) and cathode $\left(\mathrm{MnO}_{2}\right)$ and is represented as

$$
\begin{aligned}
\Delta G_{\mathrm{II}, \mathrm{III}}= & 2 F \sqrt{\frac{t}{\pi}}\left[\left(A_{\mathrm{a}} V_{\mathrm{a}} \sqrt{D_{\mathrm{a}}}\left(C_{\mathrm{a}}^{\mathrm{ini}}-C_{\mathrm{a}}^{\mathrm{aft}}\right)\right)\right. \\
& \left.+\left(A_{\mathrm{c}} V_{\mathrm{c}} \sqrt{D_{\mathrm{c}}}\left(C_{\mathrm{c}}^{\mathrm{ini}}-C_{\mathrm{c}}^{\mathrm{aft}}\right)\right)\right]
\end{aligned}
$$

where $\Delta G_{\text {II }}$ and $\Delta G_{\text {III }}$ represent the free energy change for the solid-phase diffusion of Li ions at graphite and $\mathrm{MnO}_{2}$ specifically. $\Delta G_{\mathrm{II}}$ and $\Delta G_{\mathrm{III}}$ are written individually as

$$
\begin{aligned}
& \Delta G_{\mathrm{II}}=2 F \sqrt{\frac{t}{\pi}}\left[\left(A_{\mathrm{a}} V_{\mathrm{a}} \sqrt{D_{\mathrm{a}}}\left(C_{\mathrm{a}}^{\mathrm{ini}}-C_{\mathrm{a}}^{\mathrm{aft}}\right)\right)\right] \\
& \Delta G_{\mathrm{III}}=2 F \sqrt{\frac{t}{\pi}}\left[\left(A_{\mathrm{c}} V_{\mathrm{c}} \sqrt{D_{\mathrm{c}}}\left(C_{\mathrm{c}}^{\mathrm{ini}}-C_{\mathrm{c}}^{\mathrm{aft}}\right)\right)\right]
\end{aligned}
$$

Parameters employed. $t=\frac{R^{2}}{D}$, where $R$ is the Li-ion radius in Angstroms taken to be $0.9 \AA,^{22} D$ is the thickness of the anode and considered to be $0.01 \AA$ for the calculations. The value of diffusion coefficient for $\mathrm{Li}$ ions in graphite is employed as $2.27 \times 10^{-13} \mathrm{~cm}^{2} \mathrm{~s}^{-1},{ }^{21}$ that of cathode is $1 \times 10^{-13} \mathrm{~cm}^{2} \mathrm{~s}^{-1},{ }^{21}$ and that for the concentration gradients $\left(C_{\mathrm{a}}^{\mathrm{ini}}-C_{\mathrm{a}}^{\mathrm{aft}}\right)$ and $\left(C_{\mathrm{c}}^{\mathrm{ini}}-\right.$ $C_{\mathrm{c}}^{\mathrm{aft}}$ ) before and after diffusion is assumed to be 0.1. For every State of Charge (SoC) of Li-ion intercalation at the cathode, the potential value $\left(V_{\mathrm{c}}\right)$ and deintercalation at the anode $\left(V_{\mathrm{a}}\right)$ are taken from the literature. ${ }^{22}$

$\Delta G_{\mathrm{II}}$ and $\Delta G_{\mathrm{III}}$. The values of $\Delta G_{\mathrm{II}}$ and $\Delta G_{\mathrm{III}}$ obtained are negligible, in the order of $10^{-6}$ to $10^{-7}$. The rationale behind these small values is the small variation in the $t, V$ and $\Delta C$ values. The graph of $\Delta G_{\text {II }}$ and $\Delta G_{\text {III }}$ versus SoC shows that the free energy increases with an increase in the SoC (Fig. 1).

When $t<\frac{R^{2}}{D}$, the profile of the free energy changes involved in the solid-phase diffusion of $\mathrm{Li}$ ions at the anode and cathode $\left(\Delta G_{\mathrm{II}}\right.$ and $\left.\Delta G_{\mathrm{III}}\right)$ varies as shown in Fig. 2.

Fig. 2 implicitly indicates the fact that at higher " $t$ " values, the free energy required for the diffusion process is very less. This low free energy change for the diffusion process in the solid phase is indirectly proportional to the thickness of the electrode as " $t$ " is inversely proportional to " $D$ ". Higher " $t$ " and lower " $D$ " lead to more feasible diffusion of the $\mathrm{Li}$ ions. These 

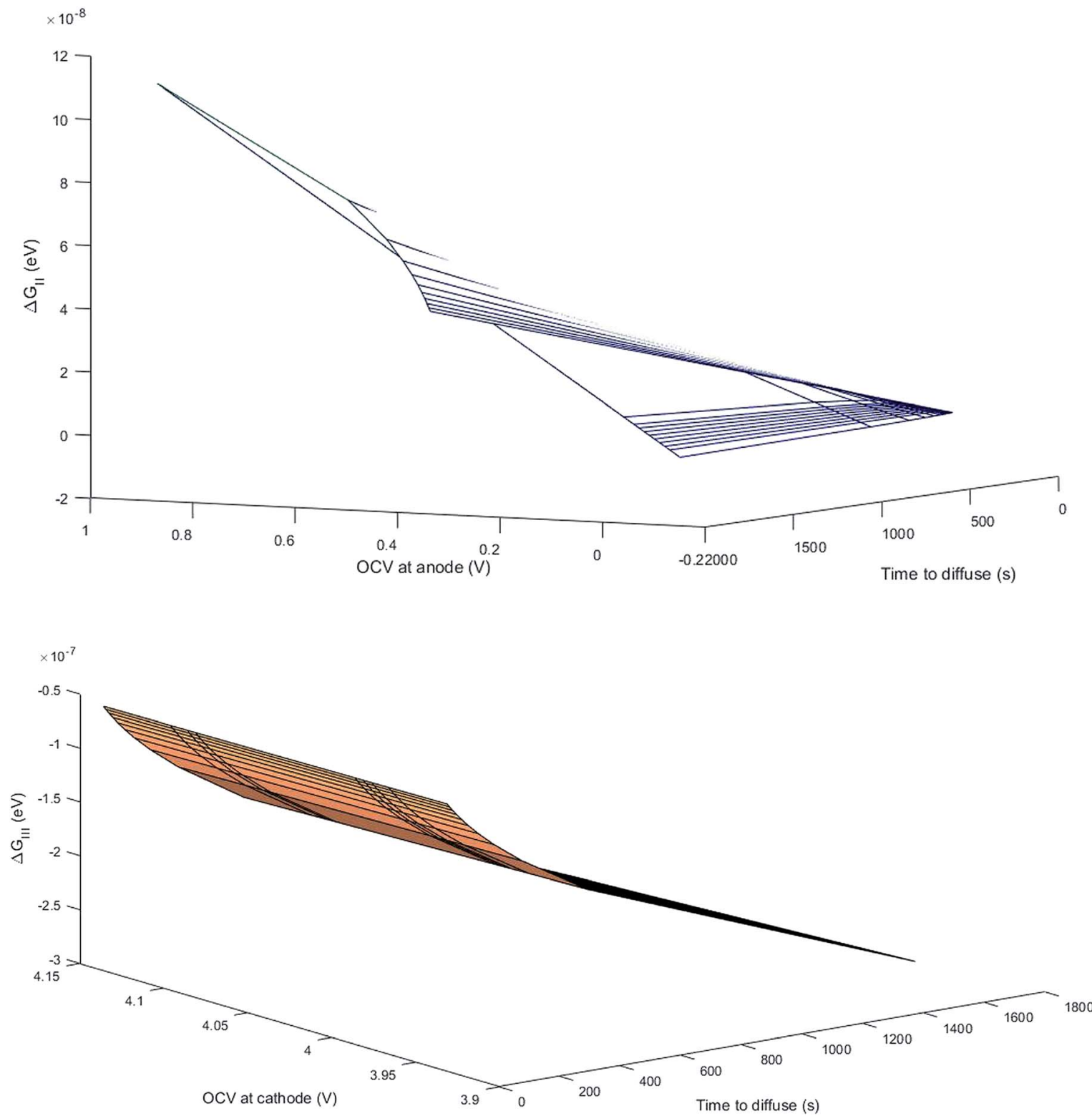

(b)

Fig. 2 Plot of $\Delta G_{\|}$and $\Delta G_{\| I}$ versus open-circuit potential at each SoC at (a) anode and (b) cathode at different $D$ values and the condition $t<\frac{R^{2}}{D}$.

results are analogous to the potentiostatic or galvanostatic intermittent techniques to determine the diffusion coefficient from the slope of charge versus time graph (Scheme 6). ${ }^{22}$

\subsection{Free energy change involved in the diffusion of $\mathrm{Li}^{+}$ions in electrolytic solution}

The third term in eqn (28) depicts the free energy change involved in the diffusion of $\mathrm{Li}$ ions in the electrolyte medium.

$$
\begin{aligned}
\Delta G_{\mathrm{IV}}= & \frac{(y-x)}{2}\left[\left(1-\frac{2}{\left(D_{\mathrm{e}, \mathrm{EC}}+D_{\mathrm{e}, \mathrm{DEC}}\right)}\right)\left(\frac{1}{r_{\mathrm{Li}^{+}}}-\frac{2}{r_{\mathrm{Li}-\mathrm{O}}}\right)\right] \\
& +\left[\left(1-\frac{2}{\left(D_{\mathrm{EC}}+D_{\mathrm{DEC}}\right)}\right)\left(\frac{2}{r_{\mathrm{Li}-\mathrm{O}}}\right)\right]
\end{aligned}
$$

where $x$ represents the fraction of Li desolvated, $y$ is the fraction of $\mathrm{Li}$ ion solvated, $D_{\mathrm{e}, \mathrm{EC}}$ and $D_{\mathrm{e}, \mathrm{DEC}}$ depict the dielectric constants of EC and DEC due to electron polarization of the solvent molecules nearest to the central $\mathrm{Li}$ ion, respectively, and $D_{\text {EC }}$ and $D_{\text {DEC }}$ are static dielectric constants of the solvents EC and DEC respectively. Eqn (39) is analogous to the Born equation $^{31}$ for solvation energetics of ions in solution.

Parameters employed. $x$ varies from 1 to 0 , and $y$ varies from 0 to $1 . D_{\mathrm{e}, \mathrm{EC}}=2.72 ; D_{\mathrm{e}, \mathrm{DEC}}=1.25 ; D_{\mathrm{EC}}=89.78 ; D_{\mathrm{DEC}}=2.82 ; r_{\mathrm{Li}^{+}}$ $=0.9 ; r_{\mathrm{Li}-\mathrm{O}}=1.26 \AA ; r_{\mathrm{EC}}=0.85 \AA ; r_{\mathrm{DEC}}=0.36 \AA$. All these values, except for those of $x$ and $y$, are taken from the literature. ${ }^{21,32,33}$ The values of $\Delta G_{\mathrm{IV}}$ calculated from eqn (39) are plotted against $x$ and $y$ to study their dependency, as shown in Fig. 3.

From Fig. 3, the dependency of hopping of Li ions in the binary solvent mixture EC/DEC via the free energy can be explained. The hopping of $\mathrm{Li}$ ions can be visualized as the interaction of $\mathrm{Li}$ ions in the ethylene carbonate/diethyl carbonate binary solvent mixture $(1: 1)$. It is mainly due to coordination bond formation between 

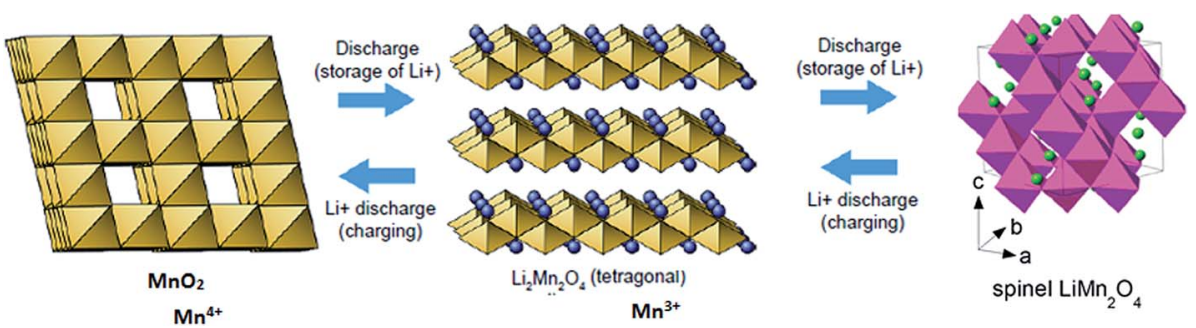

Scheme 6 Represents an illustration of the phase transition occurring at the cathode material.

$\mathrm{Li}^{+}$and hetero-atomic oxygen/carbonyl oxygen (lone pair-electrons) atoms. The number of coordination bonds formed is identical to that of solvent molecules surrounding the $\mathrm{Li}$ ions (its solvation number). The energetics involved in this process is assumed to be $0.25 \mathrm{eV}$ in the grand canonical Monte Carlo simulation of Li-ion batteries, as demonstrated elsewhere. ${ }^{21}$ From Fig. 3, we can obtain $0.25 \mathrm{eV}$ at an identical fraction of $\mathrm{Li}$ ions getting solvated and desolvated (viz-a-viz the equilibrium in the formation and breaking of Li-O bond during hopping in the solvent). The same holds true for all $x$ equal to $y$, indicating that the first principlesbased thermodynamic predictions of free energy behave as the foundation for modeling of Li-ion batteries by simulation methods such as Monte Carlo. As the dependency of $\Delta G_{\mathrm{IV}}$ on the extent of solvation/desolvation of $\mathrm{Li}$ ions is the same, the $3 \mathrm{D}$ mesh plot of $\Delta G_{\text {IV }}$ versus $x, y$ appears to be simply linear.

\subsection{Free energy change involved in the viscous drag of $\mathrm{Li}$ ions in the solvent}

$\Delta G_{\mathrm{V}}$ denotes the solvent interaction energy between the hopping Li ions in solvent EC/DEC according to the term

$$
\begin{aligned}
\Delta G_{\mathrm{V}}= & \frac{1}{2}\left\{\frac { r _ { \mathrm { EC } ^ { 3 } } } { r _ { \mathrm { Li } ^ { + } } { } ^ { 3 } } \left[\left(1-\frac{1}{D_{\mathrm{e}}^{\mathrm{EC}}}\right)\left(\frac{1}{r_{\mathrm{Li}^{+}}}-\frac{2}{r_{\mathrm{Li}-\mathrm{O}}}\right)+\left(1-\frac{1}{D^{\mathrm{EC}}}\right)\right.\right. \\
& \left.\times\left(\frac{2}{r_{\mathrm{Li}-\mathrm{O}}}\right)\right]+\frac{r_{\mathrm{DEC}^{3}}}{r_{\mathrm{Li}^{+}}{ }^{3}}\left[\left(1-\frac{1}{D_{\mathrm{e}}^{\mathrm{DEC}}}\right)\left(\frac{1}{r_{\mathrm{Li}^{+}}}-\frac{2}{r_{\mathrm{Li}-\mathrm{O}}}\right)\right. \\
& \left.\left.+\left(1-\frac{1}{D^{\mathrm{DEC}}}\right)\left(\frac{2}{r_{\mathrm{Li}-\mathrm{O}}}\right)\right]\right\}
\end{aligned}
$$

and $\Delta G_{\mathrm{VI}}$ represents the solvent interaction energy of Li ions in solvent EC/DEC when moved to a new site, as denoted by the term

$$
\Delta G_{\mathrm{VI}}=\frac{r_{\mathrm{EC}}{ }^{3} r_{\mathrm{DEC}}{ }^{3} \Delta G_{\mathrm{Li}-\mathrm{O}}^{\mathrm{form}}}{2 r_{\mathrm{Li}^{+}}{ }^{6}}
$$

where the free energy changes $\Delta G_{\mathrm{V}}$ and $\Delta G_{\mathrm{VI}}$ represent the viscous drag of the solvent on the Li ions while randomly moving in the solvent.

Parameters employed. ${ }^{21,32,33} D_{\mathrm{e}, \mathrm{EC}}=2.72 ; D_{\mathrm{e}, \mathrm{DEC}}=1.25 ; D_{\mathrm{EC}}$ $=89.78 ; D_{\mathrm{DEC}}=2.82 ; r_{\mathrm{Li}^{+}}=0.9 ; r_{\mathrm{Li}-\mathrm{O}}=1.26 ; r_{\mathrm{EC}}=0.85 ; r_{\mathrm{DEC}}=$ 0.36 . The calculated values of $\Delta G_{\mathrm{V}}$ and $\Delta G_{\mathrm{VI}}$ are 0.5938 and $0.0067 \mathrm{eV}$, respectively. Sum of $\Delta G_{\mathrm{V}}$ and $\Delta G_{\mathrm{VI}}(0.6005 \mathrm{eV})$ accounts for the energetic for viscous drag of the solvent on $\mathrm{Li}$ ions. This value is in agreement with the $E_{\text {viscousdrag }}$ calculated in the literature. ${ }^{21}$

\subsection{Free energy change involved in the process of discharge of Li-ion battery (assumption: no phase change cathode, no porosity)}

From eqn (28), the free energy change involved in the discharge process of a Li-ion battery with no phase transition cathode and highly isotropic electrode surface is calculated. The obtained value is plotted against the $\mathrm{SoC}$ of $\mathrm{Li}^{+}$at the anode and cathode. As there occurs no complication due to phase transition or porosity, the 3D mesh plot appears linear. As SoC $\mathrm{C}_{\text {anode }}$ decreases, both, $\mathrm{SoC}_{\text {cathode }}$ and $\Delta G_{\text {process }}$ increase. Hence, as seen in Fig. 4,

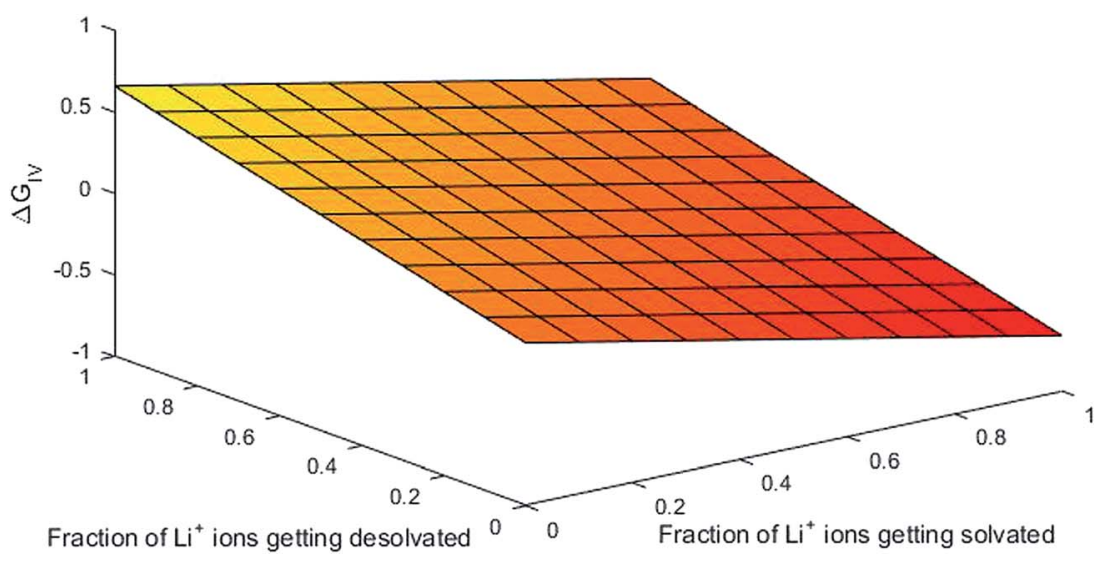

Fig. 3 Dependency of $\Delta G_{I V}$ on the solvation characteristics of Li ion. 


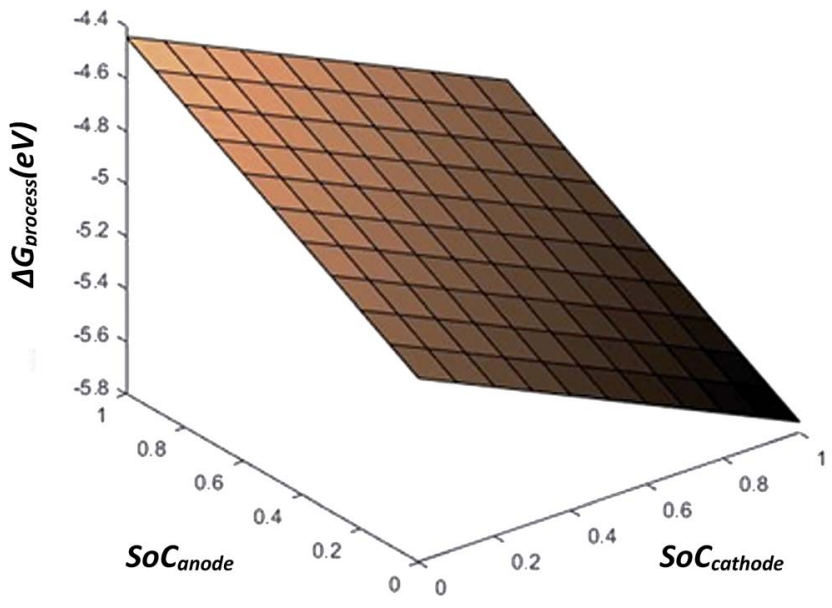

Fig. $4 \Delta G_{\text {process }}$ dependency of SoC on anode and cathode.

$$
\Delta G_{\text {process }} \propto \frac{\text { SoC }}{\text { cathode }}
$$

The value of $\Delta G_{\text {process }}$ varies from $-5.7579 \mathrm{eV}$ to $-4.4412 \mathrm{eV}$. The negative values indicate that the process of delithiation from graphite anode and lithiation into $\mathrm{MnO}_{2}$ cathode is highly spontaneous in the absence of any phase transition in the geometry of the cathode and the electrodes to be devoid of any defect and porosity.

\subsection{Free energy involved in the phase transition process at} the cathode from $\mathrm{MnO}_{2}$ to $\mathrm{Li}_{2} \mathrm{Mn}_{2} \mathrm{O}_{4}$ and $\mathrm{LiMn}_{2} \mathrm{O}_{4}$

$\Delta G_{\mathrm{VII}}$ represents the phase transition process in $\mathrm{MnO}_{2}$ upon lithiation to Li-rich $\mathrm{Li}_{2} \mathrm{Mn}_{2} \mathrm{O}_{4}$ and Li-poor $\mathrm{LiMn}_{2} \mathrm{O}_{4}$. This is represented using eqn (29) as follows:

$$
\Delta G_{\mathrm{VII}}=z \Delta G_{\mathrm{Li}-\mathrm{Mn}_{2} \mathrm{O}_{4}^{-}}^{\mathrm{form}}-(1-z) \Delta G_{\mathrm{gs}}^{\mathrm{Mn}_{2} \mathrm{O}_{4}{ }^{-}}
$$

where $\Delta G_{\mathrm{Li}-\mathrm{Mn}_{2} \mathrm{O}_{4}{ }^{-}}^{\mathrm{form}}$ and $\Delta G_{\mathrm{gs}}^{\mathrm{Mn}_{2} \mathrm{O}_{4}{ }^{-}}$represent the formation of lithiated phase and unlithiated phase at the cathode $\mathrm{MnO}_{2}$, respectively.

Parameters employed. Herein, the Li phase $(z)$ varies from 0 to $1 ; \Delta G_{\mathrm{Li}-\mathrm{Mn}_{2} \mathrm{O}_{4}{ }^{-}}^{\mathrm{form}}=4.84 \mathrm{eV}$ and $\Delta G_{\mathrm{gs}}^{\mathrm{Mn}_{2} \mathrm{O}_{4}{ }^{-}}=0.38 \mathrm{eV} .^{34}$

From Fig. 5 , it is clear that $\Delta G_{\mathrm{VII}}\left(\right.$ at $z=0$ ) is $-0.4 \mathrm{eV}$ and $\Delta G_{\mathrm{VII}}$ (at $z=1$ ) is $4.4 \mathrm{eV}$. These are not exactly the input values for the calculation of the free energy $\Delta G_{\mathrm{VII}}$. This can be attributed to the Jahn-Teller distortion occurring in the $\mathrm{MnO}_{2}$ lattice due to lithiation. As the free energy obtained at $z=0.1$ becomes the initial value for the calculation of $\Delta G_{\mathrm{VII}}$ at $z=0.2$, this residual energy can be calculated. The difference between the input and output energetics is $-0.4 \mathrm{eV}$ in the case of lower $z$ and $0.44 \mathrm{eV}$ in the case of higher $z$. Thus, the total energy difference becomes $-0.84 \mathrm{eV}$. This value is in satisfactory agreement with the Jahn-Teller distortionassociated energy in $\mathrm{LiMn}_{2} \mathrm{O}_{4}$ undergoing distortion from disordered $\mathrm{Li}-\mathrm{Mn}$ dumbbell to an inverse spinel structure upon lithiation. ${ }^{35}$ The energetics obtained is explained by the following disproportionation reaction: ${ }^{35}$

$$
2 \mathrm{Mn}_{\mathrm{oct}}^{3+} \rightarrow \mathrm{Mn}_{\mathrm{tet}}^{2+}+\mathrm{Mn}_{\mathrm{oct}}^{4+}
$$

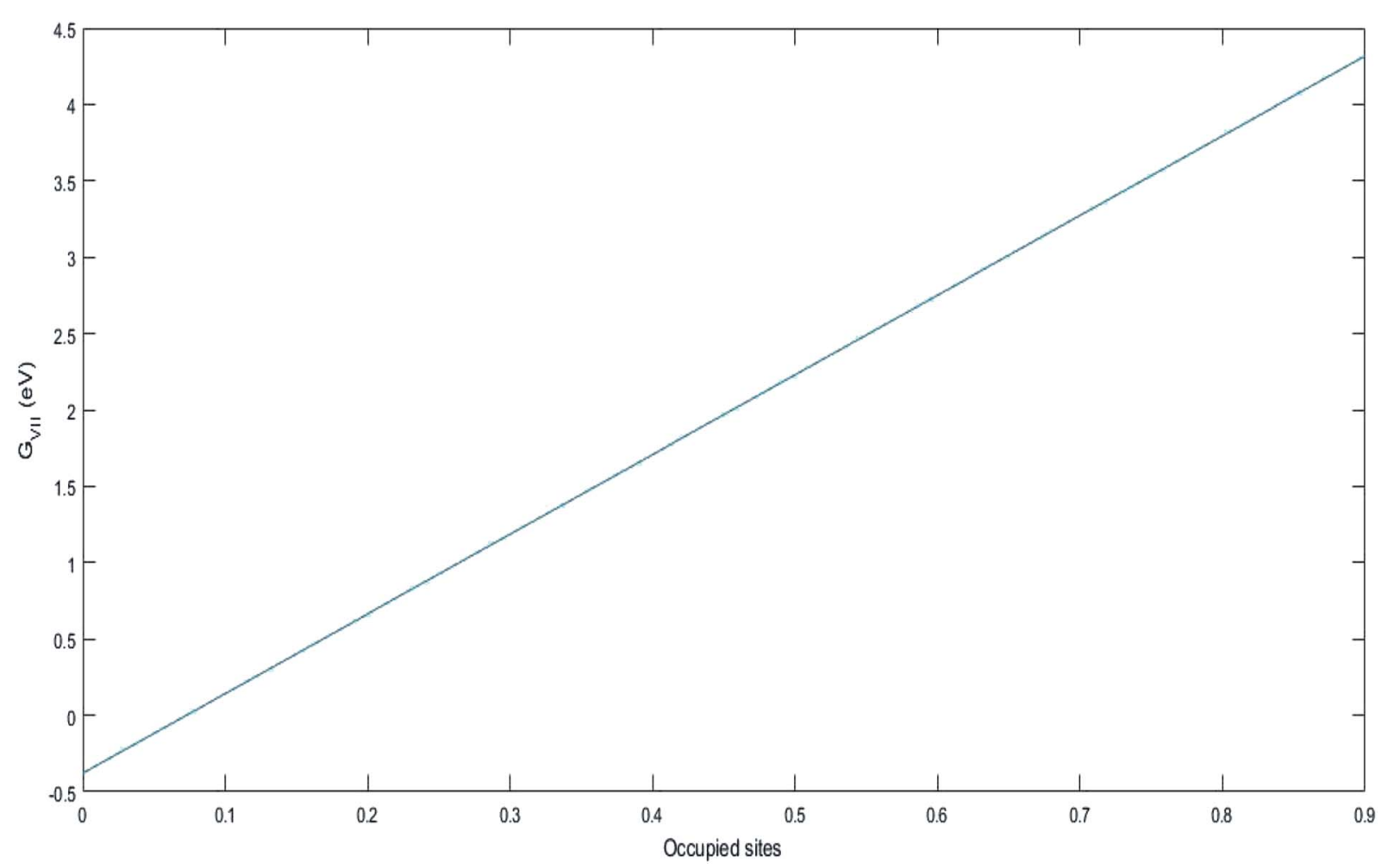

Fig. 5 Variation in free energy change involved in the phase transition at Li-rich and Li-poor cathode. 


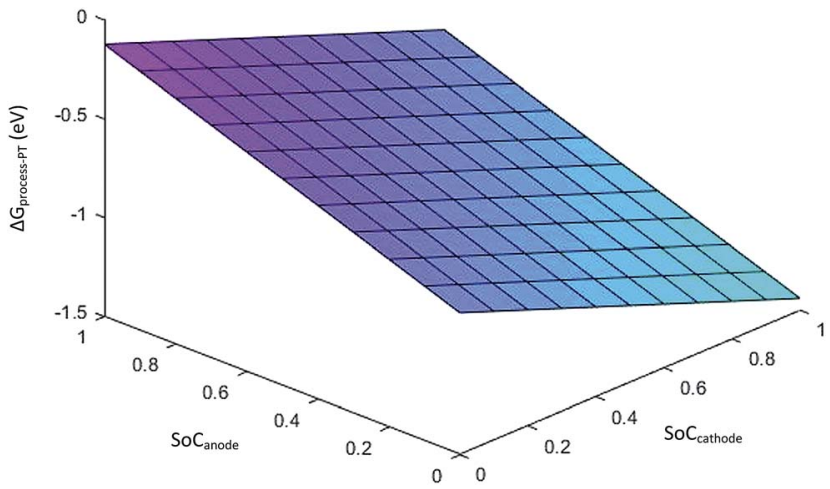

Fig. 6 Variation in $\Delta G_{\text {process }}$ with $\mathrm{SoC}_{\text {anode }}$ and $\mathrm{SoC}_{\text {cathode. }}$

3.7 Free energy change involved in the discharge process of Li-ion battery (assuming no porosity and with phase transition cathode)

Eqn (29) represents the free energy change expression for the discharge process involving phase transition cathodes. The assumption made for simplicity is no porosity in the electrodes. Fig. 6 represents the variation in $\Delta G_{\text {process }}$ with SoC at the anode and cathode.

The values of $\Delta G_{\text {process }}$ with the phase transition component are very high in comparison with those of $\Delta G_{\text {process }}$ without phase transition cathode. $\Delta G_{\text {process }}$ from eqn (29) ranges from $-1.5 \mathrm{eV}$ to 0 with variations in the $\mathrm{SoC}$ of $\mathrm{Li}^{+}$in graphite and $\mathrm{MnO}_{2}$. Thus, excess energy is needed to overcome the effect caused by the phase transformation from Lirich $\mathrm{Li}_{2} \mathrm{Mn}_{2} \mathrm{O}_{4}$ and $\mathrm{Li}$-poor $\mathrm{LiMn}_{2} \mathrm{O}_{4}$. As predicted for $\Delta G_{\text {process }}$ (without phase transition) from eqn (28), the variation in $\Delta G_{\text {process }}$ in the present case with SoC at the anode and cathode is linear. The trend of inverse proportionality prevails in the present scenario.

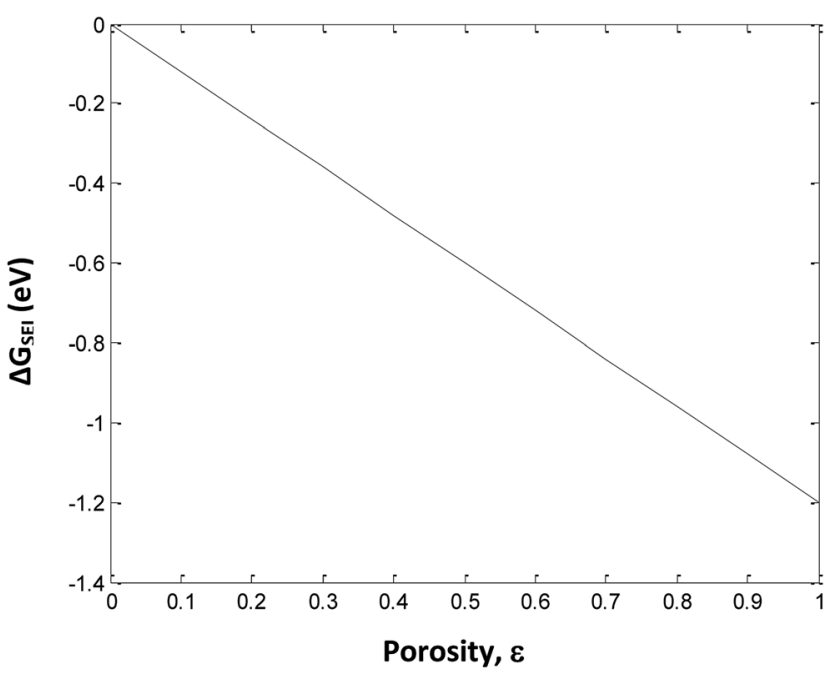

Fig. 7 Variation in $\Delta G_{\text {SEl }}$ with porosity of anode.
3.8 Variation in free energy change due to solid electrolyte interface (SEI)

The term $-\varepsilon F\left(E^{\mathrm{a} / \mathrm{e}}+E^{\mathrm{c} / \mathrm{e}}+\chi_{\mathrm{Li}}^{\mathrm{c} / \mathrm{e}}-2 \chi_{\mathrm{Li}^{+}}^{\mathrm{a} / \mathrm{e}}\right)$ from eqn (33) and (34) accounts for the solid electrolyte interface at the anode and cathode.

Assumptions made. Since the cathode material employed here is $\mathrm{LiMn}_{2} \mathrm{O}_{4}$, the SEI at the cathode is neglected. Thus, the free energy change due to SEI reduces to

$$
\Delta G_{\mathrm{SEI}}=-\varepsilon F\left(E^{\mathrm{a} / \mathrm{e}}+\chi_{\mathrm{Li}}^{\mathrm{c} / \mathrm{e}}-2 \chi_{\mathrm{Li}^{+}}^{\mathrm{a} / \mathrm{e}}\right)
$$

Parameters employed. $\varepsilon$ varies from 0 to $1 . \chi_{\mathrm{Li}}^{\mathrm{c} / \mathrm{e}}=0.2 \mathrm{eV}$, $\chi_{\mathrm{Li}^{+}}^{\mathrm{a} / \mathrm{e}}=-0.4 \mathrm{eV}$.

The values of $\Delta G_{\text {SEI }}$ vary from 0 to $-1.2 \mathrm{eV}$. This clearly indicates that the presence of SEI at the graphite anode decreases $\Delta G_{\text {process }}$, thereby making the discharge process more feasible. As seen from eqn (45),

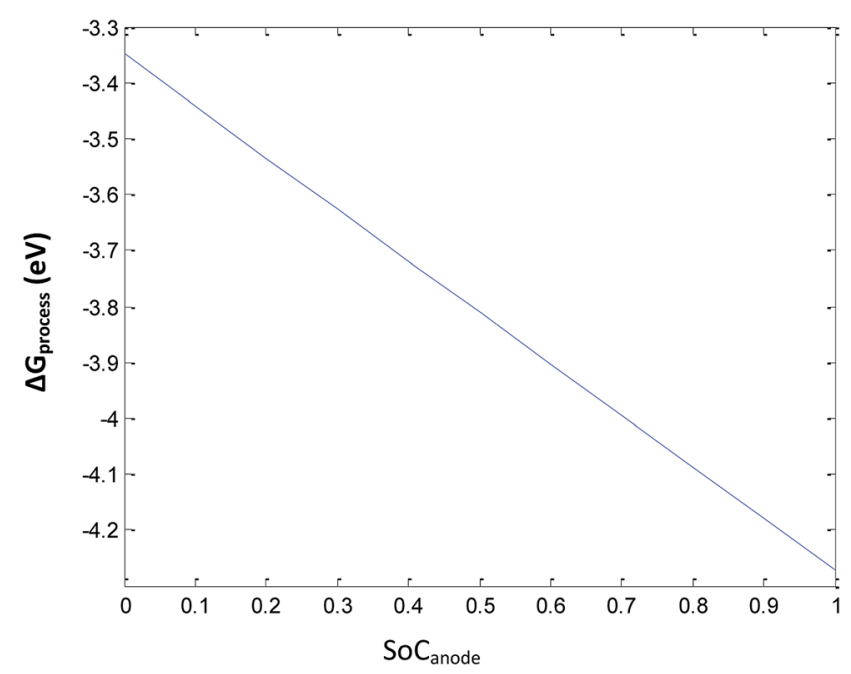

Fig. 8 Variation in $\Delta G_{\text {process }}$ with SoC of Li at the anode at 0.3 porosity.

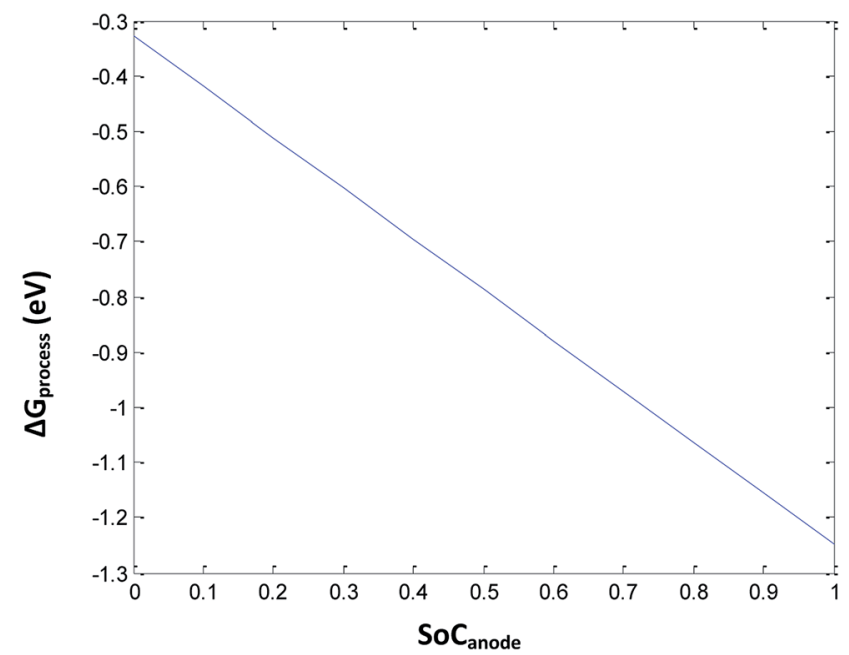

Fig. 9 Variation in $\Delta G_{\text {process }}$ with the SoC of Li at the anode at porosity $=0.3$. 


$$
\Delta G_{\mathrm{SEI}} \propto \varepsilon
$$

The free energy change involved in the formation of SEI is directly proportional to the porosity at the anode. Thus, at $\varepsilon=1$, the value of $\Delta G_{\mathrm{SEI}}=-1.2 \mathrm{eV}$, as seen from Fig. 7 .

The use of EC as a co-solvent with DEC plays a major role in the performance of a Li-ion battery by forming a protective layer on the graphite electrode. This protective layer, denoted as SEI, allows only $\mathrm{Li}$ ions to be transported to and from the graphite electrode. SEI prevents the risk of seeping of solvent molecules in the graphite electrode along with Li ions. Since, SEI is electrically insulating and sufficiently thick, it suppresses the decomposition of the electrolyte at the electrode surface. Hence, the actual deintercalation process takes place almost after $0.2 \mathrm{~V} .^{22}$ The formation energy of the insoluble Li carbonates and bicarbonates at SEI is calculated here at different porosity values.

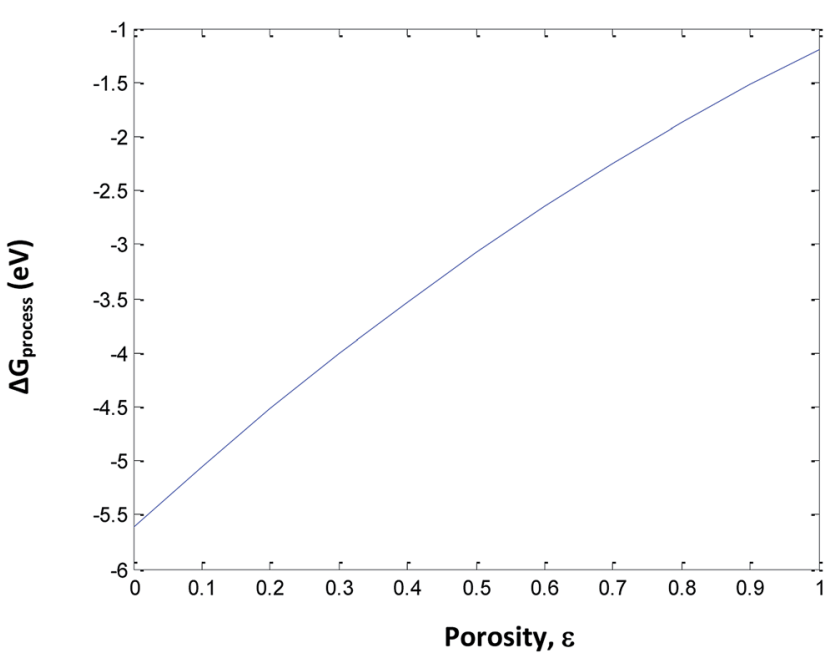

Fig. 10 Variation in $\Delta G_{\text {process }}$ with porosity of anode.

\subsection{Free energy change with constant porosity, SEI and SoC} variation but no phase transition

Eqn (33) represents the free energy change involved in the discharge process of the Li-ion battery at $\varepsilon=0.3$ of the anode. The $\Delta G_{\text {SEI }}$ value at $\varepsilon=0.3$ is $0.36 \mathrm{eV}$ (Fig. 7). Eqn (33) leads to $\Delta G_{\text {process }}$ values from $-4.2870 \mathrm{eV}$ to $-3.3653 \mathrm{eV}$. The higher negative values of $\Delta G_{\text {process }}$ indicate a more feasible discharging process when the porosity is maintained constant at 0.3. The variation in $\Delta G_{\text {process }}$ with SoC of the anode is linear, indicating the direct proportionality of SoC with $\Delta G_{\text {process }}$ (Fig. 8), similar to that presented in previous sections.

Fig. 8 shows that at very high SoC (unity), $\Delta G_{\text {process }}$ becomes $-4.287 \mathrm{eV}$. Hence, more Li ions tend to deintercalate. As SoC decreases, the spontaneity of the process decreases, and when

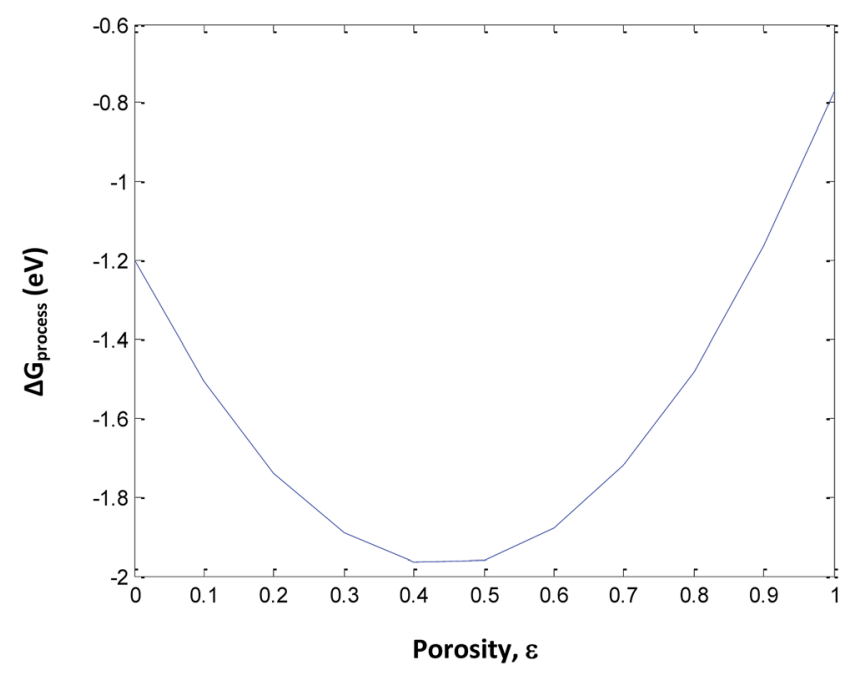

Fig. 12 Variation in $\Delta G_{\text {process }}$ with porosity of the anode including phase transition of the cathode.

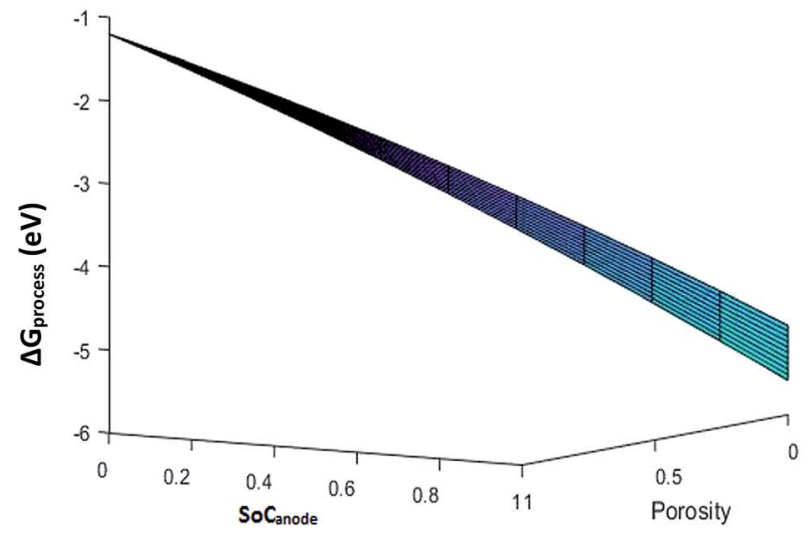

(a)

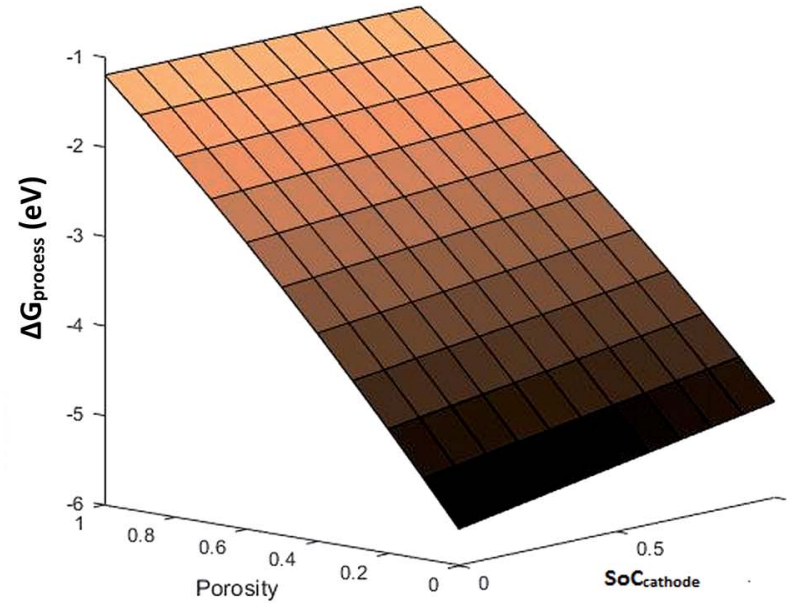

(b)

Fig. 11 Free energy variation with porosity and (a) $\mathrm{SoC}_{\text {anode }}$ and (b) $\mathrm{SoC}_{\text {cathode. }}$ 


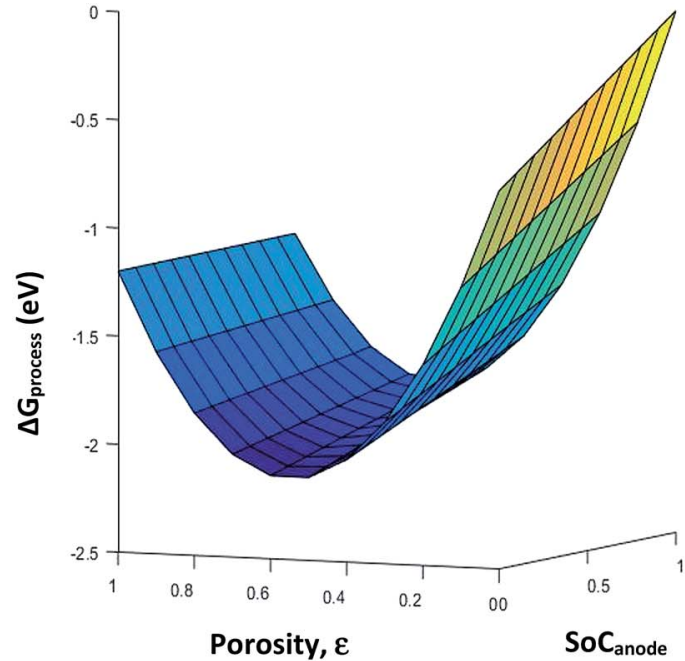

(a)

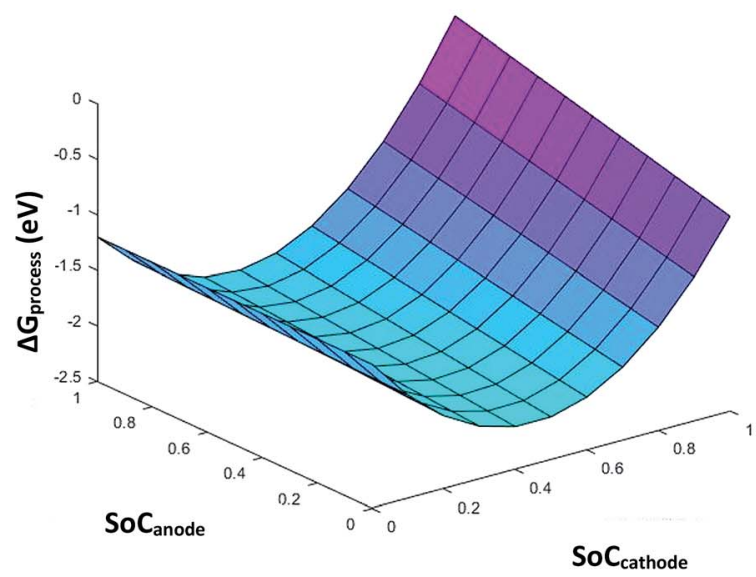

(c)

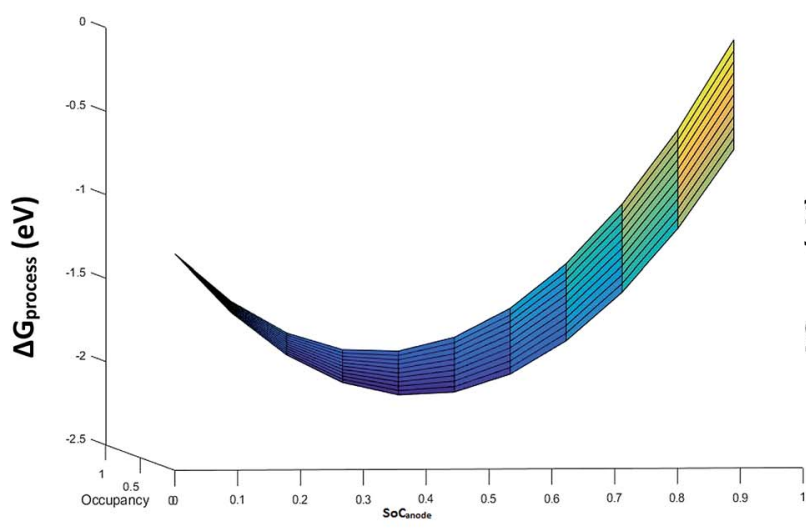

(e)

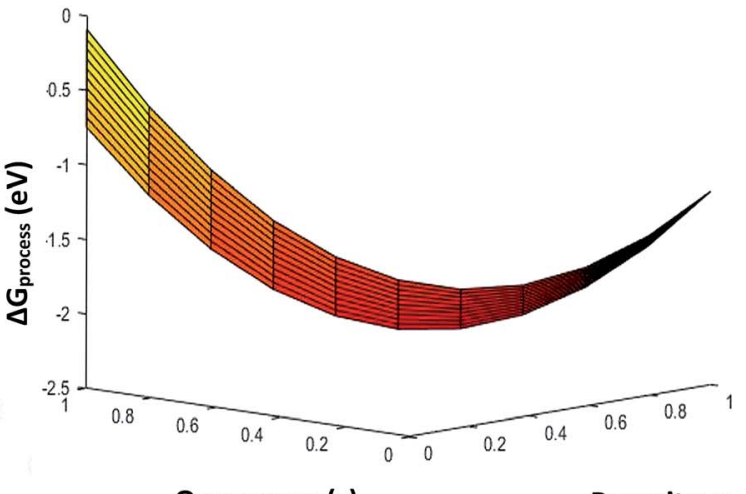

(b)

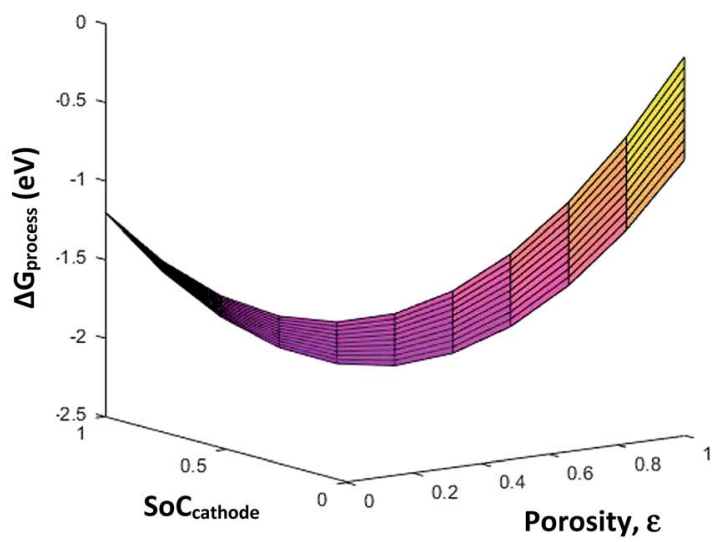

(d)

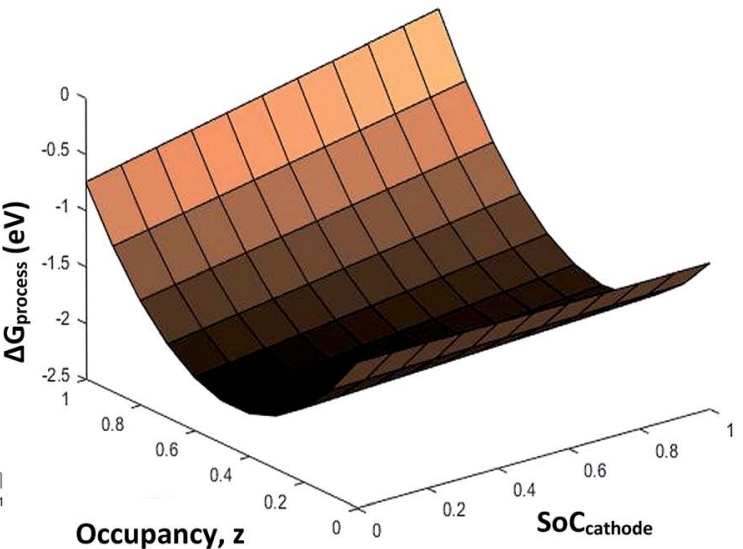

(f)

Fig. 13 Variation in free energy change of the process (a) with porosity and $\mathrm{SoC}_{\text {anode, }}$ (b) with porosity and occupancy, (c) with SoC $\mathrm{C}_{\text {anode }}$ and SoC $\mathrm{C}_{\text {cathode, }}(\mathrm{d})$ with porosity and $\mathrm{SoC}_{\text {cathode, }}(\mathrm{e})$ with $\mathrm{SoC}_{\text {anode }}$ and occupancy, $z$, and (f) with SoC $\mathrm{C}_{\text {cathode }}$ and occupancy, $z$. 
all Li ions have deintercalated from graphite $(\mathrm{SoC}=0), \Delta G_{\text {process }}$ increases by $0.9217 \mathrm{eV}$. As porosity is the reason behind SEI formation, for decrease in the $\mathrm{SoC}$ of $\mathrm{Li}^{+}$at the anode with porosity $=0.3$, the decrease in $\Delta G_{\text {process }}$ is anticipated.

\subsection{Free energy change involved in the discharge process for cathode with phase transition and 0.3 porosity and anode with 0.3 porosity}

Eqn (34) includes the terms of porosity, phase transition, and SEI for the free energy change involved in the discharge process of a Li-ion battery. Herein, the porosity is kept constant at 0.3. By introducing complications due to phase transition, porosity, and SEI, $\Delta G_{\text {process }}$ increases tremendously, making the process less and less spontaneous. The $\Delta G_{\text {process }}$ value is calculated to be from -0.3 to $-1.3 \mathrm{eV}$ for an SoC from 0 to 1 for $\mathrm{Li}$ ions (Fig. 9).

\subsection{Free energy change involved in the discharge process of Li-ion battery with porosity varying from 0 to 1 and no phase transition at cathode}

To understand the effect of porosity, SEI and phase transition independently, eqn (33) is used to calculate $\Delta G_{\text {process }}$ at different SoCs and porosities. The porosity value varies from 0 to 1 and the SoC of the cathode and anode varies from 0 to 1 . The phase transition at the cathode is neglected to minimize the variable parameters. The plot of $\Delta G_{\text {process }}$ with porosity (Fig. 10 and 11) indicates that as the porosity at the anode increases, $\Delta G_{\text {process }}$ increases linearly, thereby making the process less spontaneous. This is contrary to what is understood about porosity and $\Delta G_{\text {process }}$ as discussed in literature of Li-ion batteries. This anomaly can be attributed to the assumption of phase transition energetics in $\Delta G_{\text {process }}$ calculation. $\Delta G_{\text {process }}$ varies from $-1 \mathrm{eV}$ to $-6 \mathrm{eV}$ for $\varepsilon$ ranging from 0 to 1 . This is the highest range for $\Delta G_{\text {process }}$ obtained so far in the present calculations, indicating that Jahn-Teller distortion and the disproportionation reactions associated with it form a critical factor in reducing $\Delta G_{\text {process }}$ and making the discharge process spontaneous.

\subsection{Free energy change involved in the discharge process of Li-ion battery with porosity varying from 0 to 1 and incorporating phase transition at cathode}

The following assumptions are made in eqn (34): (i) incorporation of Jahn-Teller distortion and phase transition effects, (ii) SEI effects, (iii) porosity effects, and (iv) SoC effects on $\Delta G_{\text {process }}$. Fig. 12 implies that upon varying all parameters, the maximum tolerable porosity with minimum $\Delta G_{\text {process }}$ can be obtained. The threshold porosity value for $\mathrm{LiMnO}_{2}{ }^{-}$and graphite-based batteries is predicted to be $0.4-0.5$. This is in satisfactory agreement with the experimental data reported in the literature. The $\Delta G_{\text {process }}$ value decreases initially with an increase in porosity from $-1.2 \mathrm{eV}$ to $-2 \mathrm{eV}$. After reaching a porosity of 0.5 , $\Delta G_{\text {process }}$ increases from -2 to $-0.8 \mathrm{eV}$. Thus, the porosity behavior is directly proportional to $\Delta G_{\text {process }}$ till 0.5 and inversely proportional to $\Delta G_{\text {process }}$ after 0.5 . This behavior also reflects the Jahn-Teller distortion-induced phase transition in
$\mathrm{MnO}_{2}$ upon lithiation. It is very well demonstrated in the literature ${ }^{21,22}$ that till $0.5 \mathrm{SoC}, \mathrm{Li}^{+}$ions occupy $\mathrm{NN}$ sites, and beyond 0.5 , they occupy NNN sites. Thus, Fig. 12 predicts the phase transition of the cathode as well.

The porosity threshold of the system (ca. 0.4 to 0.5 ), JahnTeller distortion at the cathode due to the insertion of $\mathrm{Li}$ ions (viz-a-viz. $\Delta G_{\text {process }}$ variation with the SoC of graphite and $\mathrm{LiMn}_{2} \mathrm{O}_{4}$ before and after 0.5 value; Fig. 13c), and site occupancy of $\mathrm{Li}$ ions in the $\mathrm{MnO}_{2}$ lattice upon lithiation (Fig. 13b, e and f) show an exponential increase in $\Delta G_{\text {process }}$ after 0.5 SoC and $z$, as predicted via eqn (34). Thus, eqn (34) is a comprehensive thermodynamic equation for the discharge process of a Li-ion battery. Although this equation takes bulk parameters as input values, the variation in $\Delta G_{\text {process }}$ with all parameters such as SoC (both cathode and anode), occupancy of $\mathrm{Li}^{+}$ions in cathode $(z)$, phase transition in the cathode material due to lithiation, maximum threshold porosity acceptable in the anode, SEI, and its significance are demonstrated clearly for $\mathrm{LiMn}_{2} \mathrm{O}_{4^{-}}$and graphite electrode-based Li-ion batteries.

\section{Perspectives and summary}

A series of thermodynamic parameters of Li-ion batteries during the charge-discharge process, such as enthalpy change, entropy change, and Gibbs free energy change, were achieved through the study of thermo-electrochemistry. These experimental results provided basic data for the battery thermal management and a new technique for a comprehensive evaluation of the thermal and electric performance of battery materials. ${ }^{36}$ Thus, a phenomenological thermodynamic approach to calculate $\Delta G_{\text {process }}$ involved in the discharge process of a Li-ion battery was developed. The free energy change involved in Li-ion deintercalation at the anode (graphite) and intercalation at the cathode $\left(\mathrm{MnO}_{2}\right)$ was estimated as $-5.7 \mathrm{eV}$ from eqn (28), which is the negative sum of the work function of the cathode and anode. The free energy change involved in the Li-ion diffusion at the anode (graphite) and cathode $\left(\mathrm{MnO}_{2}\right)$ is negligible in the order of $10^{-6}$ to $10^{-7}$. The rationale behind these small values is the small variation in the $t, V$ and $\Delta C$ values with SoC of Li ions in respective electrodes. At higher " $t$ " values, the free energy involved in the diffusion process is very less and indirectly proportional to the electrode thickness. Higher " $t$ " and lower " $D$ " lead to more feasible diffusion of the Li ions. These results are analogous to the potentiostatic or galvanostatic intermittent techniques demonstrated in the literature, to determine the diffusion coefficient of Li ions. ${ }^{22}$ Energetics for viscous drag of the solvent on the Li ions obtained as $0.6005 \mathrm{eV}$ is in agreement with the $E_{\text {viscousdrag }}$ calculated in the literature, ${ }^{21}$ employing grand canonical Monte Carlo simulations. The energy involved in the effect of Jahn-Teller distortion on the cathode material is accurately predicted as $-0.84 \mathrm{eV}$. The maximum threshold for porosity is 0.4 to 0.5 for the anode. The phase transition is predicted to occur at $0.5 \mathrm{SoC}$ of $\mathrm{Li}$ ions at the cathode. Thus, the free energy involved in the discharge process of Li-ion batteries with $\mathrm{LiMn}_{2} \mathrm{O}_{4}$ cathode material is calculated by employing the energetic of individual processes such as intercalation/ deintercalation, diffusion of $\mathrm{Li}$ ions in solid and liquid 
phases, Jahn-Teller distortion of cathode material, the maximum threshold porosity, and SoC for phase transition via phenomenological thermodynamic analysis of the system. As a future perspective, eqn (28)-(34) can be extended to evaluate the discharge processes of Li-ion batteries involving any combination of anode and cathode materials with or without phase transition, as done via the first principles calculations in the literature. ${ }^{37}$ Measurement of the heat effect by electrochemical calorimetry plays an important role in Li-ion cell safety. ${ }^{38}$ As eqn (28)-(34) derived in the present study are temperature dependent, the thermodynamic approach presented herein for $\mathrm{LiMn}_{2} \mathrm{O}_{4}$ can be extended to understand the temperature effect on the parameters, and hence, the thermal safety of a wide variety of cathode and anode materials.

\section{References}

1 V. Ramadesigan, P. W. C. Northrop, S. De, S. Santhanagopalan, R. D. Braatz and V. R. Subramanian, J. Electrochem. Soc., 2012, 159, R31.

2 G. Ceder, Y.-M. Chiang, D. R. Sadoway, M. K. Aydinol, Y.-I. Jang and B. Huang, Nature, 1998, 392, 694.

3 J. Newman and K. E. Thomas-Alyea, Electrochemical Systems, PrenticeHall, Inc., Englewood Cliffs, NJ, 3rd edn, 2004.

4 P. DeVidts and R. E. White, J. Electrochem. Soc., 1997, 144, 4.

5 M. Doyle, T. F. Fuller and J. Newman, J. Electrochem. Soc., 1993, 140, 1526.

6 M. Doyle, A. S. Gozdz, C. N. Schmuts, J. Marie Tarascon and J. Newman, J. Electrochem. Soc., 1996, 143, 44.

7 V. Srinivasan and J. Newman, J. Electrochem. Soc., 2004, 151, A1517.

8 S. Dargaville and T. W. Farrell, J. Electrochem. Soc., 2010, 157, A830.

9 V. Indrajeet, T. Joshi, K. Zaghib, J. N. Harb and D. R. Wheeler, J. Electrochem. Soc., 2011, 158, A1185.

10 W. Dreyer, J. Jamnik, C. Guhlke, R. Huth, J. Moskon and M. Gaberscek, Nat. Mater., 2010, 9, 448.

11 D. Dreyer, C. Guhlke and R. Huth, Phys. D, 2011, 240, 1008.

12 P. Bai, D. Cogswell and M. Z. Bazant, Nano Lett., 2011, 11, 4890.

13 D. A. Cogswell and M. Z. Bazant, ACS Nano, 2012, 6, 2215.

14 M. Smith, R. Edwin Garcia and Q. C. Horn, J. Electrochem. Soc., 2009, 156, A896.

15 V. T. Indrajeet, D. E. Stephenson, N. A. Zacharias, K. Zaghib, J. N. Harb and D. R. Wheeler, J. Power Sources, 2009, 188, 592.
16 R. Theidmann, O. Stenzel, A. Spettl, P. R. Shearing, S. J. Harris, N. P. Brandon and V. Schmidt, Comput. Mater. Sci., 2011, 50, 3365.

17 D. Kehrwald, P. R. Shearing, N. P. Brandon, P. K. Sinha and S. J. Harris, J. Electrochem. Soc., 2011, 158, A1393.

18 N. Balke, S. Jesse, A. N. Morozovska, E. Eliseev, D. W. Chung, Y. Kim, L. Adamczyk, R. E. Garca, N. Dudney and S. V. Kalinin, Nat. Nanotechnol., 2010, 5, 749.

19 K. Weichert, W. Sigle, P. A. van Aken, J. Jamnik, C. Zhu, R. Amin, T. Acarturk, U. Starke and J. Maier, J. Am. Chem. Soc., 2012, 134, 2988.

20 R. Malik, F. Zhou and G. Ceder, Nat. Mater., 2011, 10, 587.

21 P. Yu, B. N. Popov, J. A. Ritter and R. E. White, J. Electrochem. Soc., 1999, 146, 8.

22 P. Kar and S. Harinipriya, J. Electrochem. Soc., 2014, 161, A726.

23 J. O. '. M. Bockris and B. E. Conway, Modern Aspects of Electrochemistry, Academic Press, New York, 1954, ch. 1, vol. 1.

24 S. Harinipriya, V. Sudha and M. V. Sangaranarayanan, Langmuir, 2004, 20, 1871.

25 I. F. Fritsch and R. L. A. Faulkner, J. Electroanal. Chem., 1989, 263, 237.

26 R. Darling and J. Newman, J. Electrochem. Soc., 1999, 146, 3765.

27 A. Yamada, J. Solid State Chem., 1996, 122, 160.

28 A. Yamada, K. Miura, K. Hinokuma and M. Tanaka, J. Electrochem. Soc., 1995, 142, 2149.

29 R. J. Gummow, A. de Kock and M. M. Thackeray, Solid State Ionics, 1994, 69, 59.

30 N. Ooi, A. Rairkar and J. B. Adams, Carbon, 2006, 44, 231.

31 M. Born, Z. Phys., 1920, 1, 45.

32 Y. Wang, S. Nakamura, M. Ue and P. B. Balbuena, J. Am. Chem. Soc., 2001, 123, 11708.

33 E. Niki, Y. Kamiya and N. Ohta, Bull. Chem. Soc. Jpn., 1969, 42, 3578.

34 K. Haong, Adv. Condens. Matter Sci., 2014, 1.

35 J. Reed, G. Ceder and A. Van Der Ven, ECS Solid State Lett., 2001, 4, A78.

36 L. Song, Z. Xiao and Y. Zhou, Electrochim. Acta, 2013, 114, 611.

37 L. Song, Z. Tang, Y. Chen, Z. Xiao, L. Li, H. Zheng, B. Li and Z. Liu, Ceram. Int., 2016, 42, 8537.

38 L. Song, X. Li, Z. Wang, H. Guo, Z. Xiao, F. Zhang and S. Peng, Electrochim. Acta, 2013, 90, 461. 